Environmental Pollution

August 2016, Volume 215 Pages 223-233

http://dx.doi.org/10.1016/i.envpol.2016.05.018

http://archimer.ifremer.fr/doc/00335/44582/

(C) 2016 Elsevier Ltd. All rights reserved.

\title{
Microplastics in seafood: Benchmark protocol for their extraction and characterization
}

\author{
Dehaut Alexandre ${ }^{1}$, Cassone Anne-Laure ${ }^{2}$, Frère Laura ${ }^{2}$, Hermabessiere Ludovic ${ }^{1}$, \\ Himber Charlotte ${ }^{1}$, Rinnert Emmanuel ${ }^{3}$, Rivière Gilles ${ }^{4}$, Lambert Christophe ${ }^{2}$, Soudant Philippe ${ }^{2}$, \\ Huvet Arnaud ${ }^{5}$, Duflos Guillaume ${ }^{1}$, Paul-Pont Ika ${ }^{2, *}$
}

\footnotetext{
' ANSES, Laboratoire de Sécurité des Aliments, Boulevard du Bassin Napoléon, 62200 Boulogne-surMer, France

${ }^{2}$ Laboratoire des Sciences de l'Environnement Marin (LEMAR), UMR6539/UBO/CNRS/IRD/IFREMER, Institut Universitaire Européen de la Mer, Technopôle Brest-Iroise, Rue Dumont d'Urville, 29280

Plouzané, France

${ }^{3}$ IFREMER, Laboratoire Détection, Capteurs et Mesures (LDCM), Centre Bretagne, ZI de la Pointe du Diable, CS 10070, 29280 Plouzané, France

${ }^{4}$ ANSES, Direction d'Evaluation des Risques, 14 Rue Pierre et Marie Curie, 94701 Maisons-Alfort

Cedex, France

${ }^{5}$ IFREMER, Laboratoire des Sciences de l'Environnement Marin (LEMAR), UMR

6539/UBO/CNRS/IRD/IFREMER, 29280 Plouzané, France

* Corresponding author : Ika Paul-Pont, email address : ika.paulpont@univ-brest.fr
}

\begin{abstract}
:
Pollution of the oceans by microplastics $(<5 \mathrm{~mm})$ represents a major environmental problem. To date, a limited number of studies have investigated the level of contamination of marine organisms collected in situ. For extraction and characterization of microplastics in biological samples, the crucial step is the identification of solvent(s) or chemical(s) that efficiently dissolve organic matter without degrading plastic polymers for their identification in a time and cost effective way. Most published papers, as well as OSPAR recommendations for the development of a common monitoring protocol for plastic particles in fish and shellfish at the European level, use protocols containing nitric acid to digest the biological tissues, despite reports of polyamide degradation with this chemical. In the present study, six existing approaches were tested and their effects were compared on up to 15 different plastic polymers, as well as their efficiency in digesting biological matrices. Plastic integrity was evaluated through microscopic inspection, weighing, pyrolysis coupled with gas chromatography and mass spectrometry, and Raman spectrometry before and after digestion. Tissues from mussels, crabs and fish were digested before being filtered on glass fibre filters. Digestion efficiency was evaluated through microscopical inspection of the filters and determination of the relative removal of organic matter content after digestion. Five out of the six tested protocols led to significant degradation of plastic particles and/or insufficient tissue digestion. The protocol using a $\mathrm{KOH} 10 \%$ solution and incubation at $60^{\circ} \mathrm{C}$ during a $24 \mathrm{~h}$ period led to an efficient digestion of biological tissues with no significant degradation on all tested polymers, except for cellulose acetate. This protocol appeared to be the best compromise for extraction and later identification of microplastics in biological samples and should be implemented in further monitoring studies to ensure relevance and comparison of environmental and seafood product quality studies.
\end{abstract}


Graphical abstract :

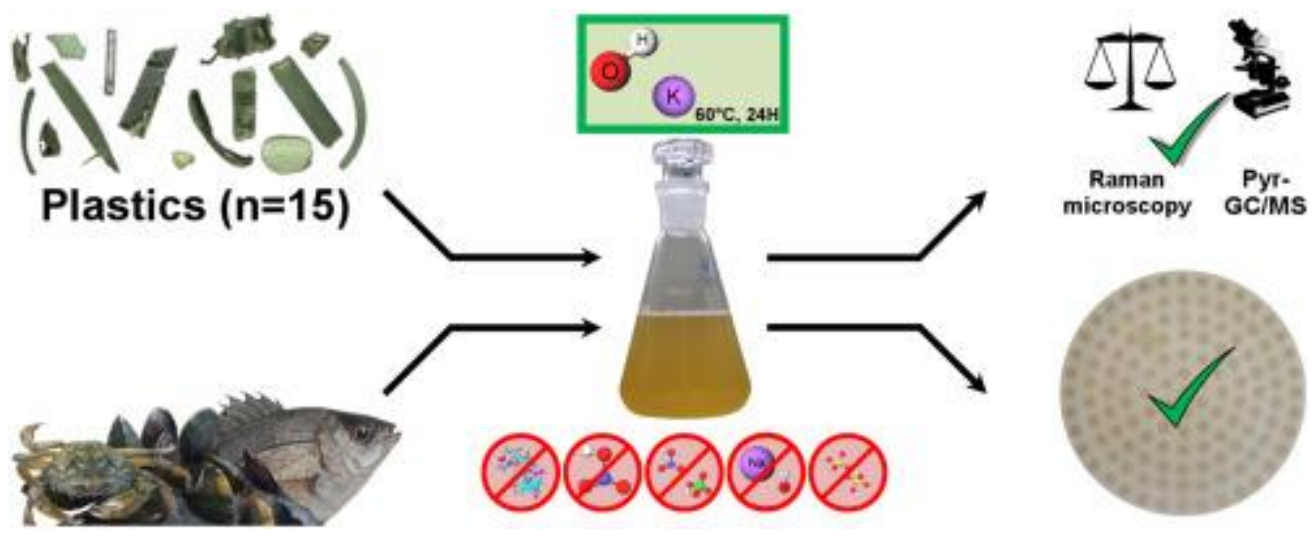

\section{Highlights}

- Integrity of 15 plastics were tested using six protocols of digestion. Protocols using $\mathrm{HNO}_{3}$ led to significant polyamide degradation. $\mathrm{KOH} 10 \%$ solution does not affect the integrity of all tested plastics except for CA. $\mathrm{KOH} 10 \%$ provides effective digestion of mussel, crab \& fish tissues. $\mathrm{KOH}$ $10 \%$ is the best compromise for extraction and identification of microplastics.

\section{Abbreviations}

- CA, Cellulose Acetate;

- ePS, expanded Polystyrene;

- GC, Gas chromatography;

- $\mathrm{HCl}, \mathrm{Hydrochloric} \mathrm{acid;}$

- HDPE, High Density Polyethylene;

- LDPE, Low Density Polyethylene;

- MS, Mass Spectrometry;

- PA, Polyamide;

- PA-12, Polylauryllactam;

- PA-6, Polycaprolactam;

- PC, Polycarbonate;

- PE, Polyethylene;

- PET, Polyethylene terephthalate;

- PMMA, Poly(methyl-methacrylate);

- PP, Polypropylene;

- PS, Polystyrene;

- PTFE, Polytetrafluoroethylene;

- PUR, Polyurethane;

- Pyr, Pyrolysis;

- PSXL, crosslinked Polystyrene;

- uPVC, unplasticized Polyvinyl Chloride

Keywords : Microplastics, Digestion, Method, Seafood products, Tissue, Plastic integrity 


\section{Introduction}

Worldwide annual production of plastics has been steadily increasing since 1950 and was estimated at 311 million tons in 2014 (PlasticsEurope, 2015). Plastics include more than twenty families of polymers among which six are referred to as the "big six": polypropylene (PP), high- and low-density polyethylene (HDPE \& LDPE), polyvinyl chloride (PVC), polyurethane (PUR), polyethylene terephthalate (PET) and polystyrene (PS) and correspond to $80 \%$ of the plastic production in Europe (PlasticsEurope, 2015). Very little plastic is recycled and it fragments or degrades at a very slow rate, thus accumulating in all environments. The first observations of microplastic pollution in marine ecosystems were recorded in 1972 (Carpenter et al., 1972). More recently, it has been estimated that $10 \%$ of plastics produced end up in oceans (Thompson, 2006), comprising $60 \%$ to $80 \%$ of the marine litter (Laist, 1987; Moore, 2008). From the surface to the ocean floor, studies have described between 7000 tons and 250,000 tons of plastics floating at the surface of seawater (Cozar et al., 2014; Eriksen et al., 2014), in the water column (Lattin et al., 2004) and in seabed sediments (Fischer et al., 2015; Fries et al., 2013; Van Cauwenberghe et al., 2013). Plastics in oceans are encountered in macro- (>25 mm), meso- $(5-25 \mathrm{~mm})$ and microplastic forms $(<5 \mathrm{~mm})$ (Arthur et al., 2009; Shim and Thompson, 2015; Thompson, 2004). Primary microplastics are referred to as microparticles produced as such, i.e. plastic pellets, exfoliating cosmetics or synthetic clothing fibres (Chang, 2015; Napper et al., 2015; Mato et al., 2001; van Wezel et al., 2015), while secondary microplastics derive from the breakdown of larger plastic debris (Browne et al., 2007; Cole et al., 2011; Shah et al., 2008; Thompson, 2004).

Ingestion of microplastics has been shown in laboratory and field studies for numerous marine organisms including zooplankton, worms, bivalves, crustaceans, demersal and pelagic fish, seabirds, reptiles and mammals (Codina-García et al., 2013; Cole et al., 2013, 2014; De Witte et al., 2014; Lusher, 2015; Lusher et al., 2013, 2015; Moore et al., 2001; Sussarellu et al., 2016; Tourinho et al., 2010; Van Cauwenberghe and Janssen, 2014; Van Cauwenberghe et al., 2015; Watts et al., 2014). Studies of fish have found between $2 \%$ to $40 \%$ of individuals to be contaminated, with a mean number of particles from 1 to 7.2 per individual (Boerger et al., 2010; Foekema et al., 2013; Lusher et al., 2013). 
For molluscs and especially Mytilus edulis, this microplastic load was reported to vary from 0.2 to 0.5 plastic particles per gram of tissue, leading to an average number being around one particle per individual (De Witte et al., 2014; Van Cauwenberghe and Janssen, 2014). It is noteworthy that all types of fibres could not be doubtlessly assessed in these latter studies due to the use of nitric acid. Microplastic accumulation through trophic levels is suspected to occur, as has already been reported at the lower levels of the food web (Farrell and Nelson, 2013; Setälä et al., 2014).

There is a great concern surrounding microplastics in numerous environmental and food science fields of research, as these pollutants can be deleterious for biota; first by their nature as a mechanical hazard (Cole et al., 2011), and most importantly as they are suspected to transfer microorganisms or pollutants adsorbed on their surface, additives, and other toxic chemicals into the guts of organisms, which may affect physiological functions (Browne et al., 2013; Teuten et al., 2009; Thompson, 2004; Van Cauwenberghe and Janssen, 2014; Zettler et al., 2013). Microplastics might also represent a threat for human consumers through the consumption of seafood products; although potential risks for human health posed by plastics as such, or as carriers of pollutants remains undocumented (Van Cauwenberghe and Janssen, 2014). If they wrote that adsorbed pollutants should not be a threat considering the "low significance of this transport from microplastics", a greater concern arose from intrinsic additives, active at low concentrations such as phthalates, bisphenol A or flame retardants.

Numerous methods have been developed to extract microplastics from sediment and biological tissues. They can be classified as acidic (Claessens et al., 2013; De Witte et al., 2014), alkaline (Cole et al., 2014; Foekema et al., 2013), oxidizing (Nuelle et al., 2014; Avio et al., 2015) and enzymatic methods (Cole et al., 2014). However, most of these methods are not adapted for large scale monitoring as they are either time consuming or too expensive to be implemented on a large scale. As a consequence, these methods do not accurately meet, to date, the call of some international bodies such as OSPAR or the Marine Strategy Framework Directive to provide standard, effective and cost efficient analytical methods (European Commission, 2010; OSPAR, 2015). Indeed, the relatively low percentage of animals exhibiting plastics in their tissue reported so far in the literature (Lusher, 2015) implies that a high 
number of animals should be analysed for routine plastic monitoring as advised by OSPAR (OSPAR, 2015). More worrying is the often insufficient efficiency in digesting biological tissues and the damage that can potentially be observed in plastics after the digestion and extraction processes. For instance, most published papers, as well as OSPAR recommendations, are using protocols containing nitric acid to digest biological tissues, despite reports of substantial degradation of some polyamide types (Avio et al., 2015; Cole et al., 2014; OSPAR, 2015). This might lead to underestimations of microplastic loads and misinterpretations of the actual levels of contamination in marine organisms. This is especially true as polyamide (PA) is among the 10 most produced plastics, this polymer is therefore likely to be released and found in the environment. Finally, the range of tested families of plastics is often small in published studies, with little concern for the impact of the digestion procedure on plastic identification by either Raman spectroscopy, Fourier transform infrared spectroscopy, or Pyrolysis-GC/MS (Pyr-GC/MS) (Cole et al., 2014; Foekema et al., 2013; Fries et al., 2013; Lusher et al., 2014; Nuelle et al., 2014; Van Cauwenberghe et al., 2015).

The present study aims to identify a protocol to digest organic matter from biological samples that conforms to the technological limitations for large scale monitoring of microplastic contamination in fish and shellfish consumed by humans. To do so, existing and adapted methodologies were reviewed, and their limits were defined by testing: (i) polymer integrity in up to 15 plastic families through microscopic inspection and weighing; (ii) polymer identification using Pyr-GC/MS and Raman microspectrometry analyses prior to and after digestion; and (iii) efficiency in digesting biological tissues of molluscs, crustaceans and fish, achieved by filtration, visual inspection and evaluation of the remaining organic matter content on the filters. A first experiment (experiment 1) was conducted on 5 polymer types (including polyamide) to quickly rule out non-suitable digestion protocols, i.e. protocols leading to substantial degradation of polyamide and potentially other polymers. Subsequently, a more thorough experiment (experiment 2) was performed in order to test the suitable selected digestion protocols on a wider range of polymer types. Finally, the protocols identified in experiment 2 were tested on biological matrices (experiment 3). 


\section{Materials and Methods}

Out of the fifteen types of plastics tested in this study, fourteen were supplied by Goodfellow Cambridge Ltd (Lille, France) (Supplemental Table 1). These included cellulose acetate (CA), high and low density polyethylene (HDPE \& LDPE), polylauryllactam (PA-12), polycaprolactam (PA-6), polycarbonate (PC), polyethylene terephthalate (PET), poly(methyl-methacrylate) (PMMA), polypropylene (PP), polystyrene (PS), crosslinked polystyrene (PSXL), polytetrafluoroethylene (PTFE), polyurethane (PUR) and unplasticized polyvinyl chloride (uPVC). Expanded polystyrene (ePS) was collected on our own.

\subsection{Experiment 1: elimination of the non-suitable protocols}

For this preliminary study, five uncoloured, granule-like, plastics particles ( $c a .3 \mathrm{~mm}$ diameter): LDPE, HDPE, PP, PA-12 and PS were tested using the six digestion protocols described below. Three particles of each of the plastic families were weighed five times on a $1 \mathrm{mg}$ sensitivity analytical balance (Sartorius CP224S, Dourdan, France). Each sample was also photographed using an Olympus SZ61 binocular microscope mounted with a DP21 camera (Rungis, France) and 2650K light. Weighing and image capture were performed before and after application of the digestion protocols to determine their potential deleterious effects.

Six existing protocols were tested. Protocol 1 was adapted from Foekema et al. (2013): plastics were incubated for 3 weeks at room temperature $\left(21 \pm 2{ }^{\circ} \mathrm{C}\right)$ with $20 \mathrm{~mL}$ of $10 \%(\mathrm{w} / \mathrm{w})$ potassium hydroxide $(\mathrm{KOH})$ solution (Fisher Labosi, Elancourt, France). Protocol 2 was based on the study of Karl et al., (2014). Briefly a solution of $0.5 \%(\mathrm{w} / \mathrm{v})$ pepsin was prepared in $0.063 \mathrm{M}$ hydrochloric acid (HCl) (VWR, Fontenay-sous-bois, France) from a 2,000 FIP-U/g pepsin solution (Panreac, Lyon, France). Plastics were incubated for $2 \mathrm{~h}$ at $35{ }^{\circ} \mathrm{C}$ in $20 \mathrm{~mL}$ of pepsin solution in a beaker placed on a VELP Scientifica AREX heating bench (Usmate, Italy) equipped with a VTF temperature sensor to maintain the specified temperature. Protocol 3 was adapted from Van Cauwenberghe et al. (2015) \& Van Cauwenberghe and Janssen (2014). Plastics were placed in $20 \mathrm{~mL}$ of a $65 \%$ nitric acid $\left(\mathrm{HNO}_{3}\right)$ solution (Merk, Fontenaysous-Bois, France) and maintained at room temperature overnight prior to being heated at $60{ }^{\circ} \mathrm{C}$ for $2 \mathrm{~h}$ and diluted with warm $\left(80^{\circ} \mathrm{C}\right)$ distilled water. Protocol 4 was adapted from the method used by De 
Witte et al., (2014) recommended by the Convention for the Protection of the Marine Environment of the North-East Atlantic (OSPAR, 2015). Plastics were added in $20 \mathrm{~mL}$ of solution containing a 4:1 (v/v) mix of $65 \% \mathrm{HNO}_{3}$ and $65 \%$ perchloric acid $\left(\mathrm{HClO}_{4}\right)$ solutions (VWR) respectively. Tubes were left at room temperature, overnight, and were boiled for 10 min before being diluted with warm distilled water $\left(80{ }^{\circ} \mathrm{C}\right)$. Protocol 5 was adapted from the work of Cole et al., (2014): plastics were incubated at $60{ }^{\circ} \mathrm{C}$ during $24 \mathrm{~h}$ with $20 \mathrm{~mL}$ of $10 \mathrm{M}$ sodium hydroxide $(\mathrm{NaOH})$ (Sigma-Aldrich, Saint-Quentin-Fallavier, France). Protocol 6 was developed based on the method reported by Maher et al. (2002) using an oxidizing solution prepared extemporaneously, composed of $0.27 \mathrm{M}$ peroxodisulfate potassium $\left(\mathrm{K}_{2} \mathrm{~S}_{2} \mathrm{O}_{8}\right)$ (Sigma-Aldrich) and $0.24 \mathrm{M} \mathrm{NaOH}$. Plastics in oxidizing solution were incubated at $65^{\circ} \mathrm{C}$ for $24 \mathrm{~h}$. All experiments were performed in clean glass tubes, except protocol 2 that required a clean beaker.

\subsection{Experiment 2: impact of the three selected digestion protocols on the integrity of $\mathbf{1 5}$} plastic families

Only methods that exhibited acceptable results in experiment 1, i.e. no degradation of plastic polymers, and that met Marine Strategy Framework Directive and OSPAR recommendations (time effective and low cost), were kept for a more thorough study on a wider range of plastics.

\subsubsection{Protocols}

Based on the results of the preliminary study, only protocols 5 and 6 demonstrated suitable outcomes, i.e. short duration of digestion and no degradation of plastics; thus they were selected for a thorough study on a wider range of plastics. An altered protocol (Protocol 1b) was also selected after modification of protocol 1, reducing the 3 weeks at room temperature step to a $24 \mathrm{~h}$ incubation step at $60{ }^{\circ} \mathrm{C}$.

\subsubsection{Processing of plastic samples}

The range of plastic polymers tested was expanded from 5 to 15 families. Analyses were performed on 3 replicate samples per plastic family. Samples of plastic were cut with a scalpel as thin as possible to obtain small fragments $(1-5 \mathrm{~mm})$ and put into glass Petri dishes. To test the impact of the digestion 
protocols, $10 \mathrm{~mL}$ of each tested solution was poured into a Petri dish with plastic fragments and incubated without agitation. Before and after application of digestion protocols, fragments were rinsed with bi-distilled water and dried for $2.5 \mathrm{~h}$ at $50{ }^{\circ} \mathrm{C}$. A series of weighings ( $\mathrm{n}=5$ per replicate) were performed for each plastic sample on a $0.1 \mathrm{mg}$ precision analytical balance (Sartorius Genius, Dourdan, France). A photograph of each fragment was taken as described in 2.1. One replicate sample of each plastic was analysed by Raman micro-spectrometry and another one by Pyr-GC/MS in order to evaluate whether digestion protocols interfere with the identification of plastic families. All analyses (photographs, weighings, Raman micro-spectrometry and Pyr-GC/MS) were performed before and after application of digestion protocols.

\subsubsection{Plastic identification}

For Raman analysis, each particle was placed on a gold coated microscope slide and analysed using a combination of static image analysis of particles with a HORIBA Scientific LabRam HR800 Raman micro-spectrometer (Villeneuve d'Ascq, France) with laser wavelength set at $785 \mathrm{~nm}$ and a 10x Olympus objective. The analysis of particles was carried out using a combination of static image analysis of particles and automated Raman micro-spectroscopy, allowing the analysis of number, size, shape and chemical composition of a large number of particles. Polymers were identified using spectroscopy software (KnowItAll, Bio-Rad) with queries against our own database containing preestablished polymer spectra.

For Pyr-GC/MS analysis, a small piece $\left(<0.5 \mathrm{~mm}^{3}\right)$ of each sample was placed in a pyrolysis cup on the AS-1020E autosampler of a Frontier Lab EGA/PY - 3030D (Fukushima, Japan), before being pyrolysed at $600{ }^{\circ} \mathrm{C}$. Pyrolysis products were directly injected, with a split of 20, on a coupled Shimadzu GC-2010 device (Noisiel, France) and separated on a Restek RXi-5ms ${ }^{\circledR}$ column (Lisses, France). Helium was used as carrier gas with a linear velocity of $40 \mathrm{~cm} / \mathrm{s}$. The oven program was set as follows: 5 min at 40 ${ }^{\circ} \mathrm{C}$ increasing to $320{ }^{\circ} \mathrm{C}$ at $20{ }^{\circ} \mathrm{C} / \mathrm{min}$, maintained for $14 \mathrm{~min}$. Mass spectra were obtained by a Shimadzu QP2010-Plus mass spectrometer coupled to the GC. Interface temperature was fixed at 300 ${ }^{\circ} \mathrm{C}$ to prevent re-condensation, ionization voltage was set at $70 \mathrm{eV}$ and a mass range extending from 33 
to $500 \mathrm{~m} / \mathrm{z}$ was analysed with a $2000 \mathrm{~Hz}$ scan speed. Samples were identified using F-Search software

4.3, querying pyrograms against Frontier Lab's database and our own database containing preestablished pyrograms with plastic samples. Identification was established based on the similarity percentage between average mass spectra. As advised by the Pyr-GC/MS supplier, a minimal value of $80 \%$ was necessary to certify the proper identification.

\subsection{Experiment 3: application of selected digestion protocols on seafood products}

\subsubsection{Protocols}

211 Two out of the three previous protocols ( $1 \mathrm{~b}$ and 6$)$, were selected to be tested for digestion of biological tissues. A sequential approach was used: they were first tested on mussels, then on crabs and fish, and whenever a protocol was not considered as efficient on a seafood product, it was ruled out for the next product. While incubation time and temperature remained unchanged, digestion of tissues and cartilage for crabs from seafood products were carried out on a Labomoderne AG610 multi-positions magnetic hot plate stirrer (Paris, France) at $300 \mathrm{rpm}$.

\subsubsection{Seafood products}

Tissues from three different marine animals were analysed: mussels (Mytilus edulis), velvet crabs

219 (Necora puber) and black seabreams (Spondyliosoma cantharus). All tools and glassware used for the digestion tests were carefully rinsed with distilled water filtered through $90 \mathrm{~mm} \mathrm{GF} / \mathrm{A} 1.6 \mu \mathrm{m}$ glass fibre filters (Whatman, Velizy-Villacoublay, France). Water used to rinse all seafood products was systematically distilled and filtered before use. All analyses were performed on 3 individuals per species and digestion protocols. All animals were collected in the Bay of Brest (France) and stored at $-20{ }^{\circ} \mathrm{C}$ prior to analysis. Mussels $(5.4 \pm 1.3 \mathrm{~g}$, mean \pm standard deviation) were shelled, weighed and rinsed before being placed in $250 \mathrm{~mL}$ of digestion solution. Crabs were rinsed and carefully shelled. Tissues and cartilages were gathered with pliers and scalpels and weighed (5-10 g) before being placed in 250 $\mathrm{mL}$ of digestion solution. Black seabream were first sized and weighed before being rinsed, carefully gutted to extract the whole alimentary tract and filleted. Fillet $(150.7 \pm 37.3 \mathrm{~g})$ and whole alimentary 
tract $(34.9 \pm 12.8 \mathrm{~g})$ were weighed and respectively placed in $500 \mathrm{~mL}$ and $250 \mathrm{~mL}$ of digestion solution.

230 After applications of protocols, digestates were filtered through GF/A $1.6 \mu \mathrm{m}$ glass fibre filters. In the 231 case of the presence of debris in the digestate, especially for whole alimentary tract, a density-based separation step using sodium tungstate was subsequently added. Briefly, a 70\% (w/w) sodium tungstate (Acros Organics, Geel, Belgium) solution $\left(d=1.5 \mathrm{~g} / \mathrm{cm}^{3}\right)$ was added to the digestate $(2: 1, \mathrm{v} / \mathrm{v})$ right after the $24 \mathrm{~h}$ digestion. The mixture was then thoroughly stirred for 10 minutes before being left to settle for $1 \mathrm{~h}$. The supernatant, containing the floating plastic particles (Corcoran et al., 2009), was subsequently collected and filtered, as previously described.

Concerning the spiking approach described in 2.3.4, triplicate samples of cod (Gadus morhua) fillets $(23.6 \pm 3.2 \mathrm{~g})$, saithe (Pollachius virens) whole alimentary tract $(9.7 \pm 0.6 \mathrm{~g})$ and mussels $(4.0 \pm 0.9 \mathrm{~g})$ were studied.

\subsubsection{Assessment of digestion efficiencies}

The propensity of the selected protocols to properly digest flesh was assessed through microscopic inspection of filters using a Zeiss Stemi 2000-C binocular microscope (Marly-le-Roi, France). This device was mounted with a Canon EOS 600D camera and illuminated with a 2500K light. A digestion was qualified as efficient in the absence of debris, organic matters, shell or cartilage, which can hinder microplastic detection on the filter. Also, dry weight of each filter, obtained by placing filters at $60{ }^{\circ} \mathrm{C}$ for $24 \mathrm{~h}$, was measured before and after digestion to assess the proportion of remaining organic matter on each filter after digestion. Digestion efficiencies $(\% D e)$ were calculated as follows, where $\% D e$ corresponds to the digestion efficiency, $D W_{f}$ and $D W_{\text {fad }}$ correspond respectively to the dry weights (n=5) Finally, $T_{w}$ corresponds to the average weight of tissues subjected to digestion $(\mathrm{n}=50)$.

$$
\% D e=100-\left(\frac{D W_{f a d}-D W_{f}}{T_{w}} \times 100\right)
$$


253 A spiking approach was also performed to endorse protocol $1 \mathrm{~b}$. A commercial yellow fluorescent fine 254 fishing line was cut into small particles of $c a .500 \mu \mathrm{m}$. Its polymer composition was identified thanks to Pyr-GC/MS as PA-6 (94\% similarity). Ten yellow PA-6 particles were spiked in the samples of tissue with a thin sewing needle. Samples were digested for $24 \mathrm{~h}$ at $60{ }^{\circ} \mathrm{C}$ and $300 \mathrm{rpm}$ with $250 \mathrm{~mL}$ of $10 \%$ $(\mathrm{w} / \mathrm{w}) \mathrm{KOH}$. A recovery percentage was calculated with a ratio of the count of yellow particles lying on filters after filtration and the number of initially spiked particles. Finally, nylon particles recovered after digestion were analysed by Pyr-GC/MS.

\subsection{Statistics}

Results of weight measurements were represented on bar charts as means of the 5 replicates. Error bars on charts represent the expanded weighing uncertainty of the results $\left(U_{e b}\right)$, evaluated based on the recommendations of the International organization for standardization (ISO/IEC Guide 98-3, 2008).

264 This parameter provides a fine determination of uncertainty compared to the value given by the maximum permissible error and takes into account uncertainty related to reproducibility and resolution of the analytical balance.

$U_{e b}$ was estimated as follows, with $d$ being the resolution of analytical balance and $e$ the standard deviation obtained after evaluation of the reproducibility by consecutive weighing $(\mathrm{n}=50)$. Mean values with more than $0.1 \mathrm{mg}$ difference were considered as significantly different.

$$
U_{e b}=2 \times \sqrt{\left[\left(\frac{d}{2 \times \sqrt{3}}\right)^{2}+\left(\frac{e}{\sqrt{3}}\right)^{2}\right]}
$$

Size evolution was assessed using the histogram tool on GIMP 2 software (2.8.16). Briefly, each fragment area was selected and the number of pixels was recorded. A loss percentage was evaluated as a ratio of pixel numbers before and after treatment by each protocol. 


\section{Results and Discussion}

3.1 Experiment 1: elimination of the non-suitable protocols

276 This experiment aimed to test the six protocols on a small subsample of polymers, as degradation of polymers such as polyamide allows the exclusion of some of the tested protocols. Protocols 1 and 2 did not lead to any weight change (Supplemental Table 2) or plastic degradation, as confirmed by the absence of visual change. However protocol 1 could not be kept as such, due to the long extraction duration ( 3 weeks), which was considered to be too constraining to be performed routinely and on a large scale. Although having proved to be effective for research of parasites in fish fillets (Karl et al., 2014), and having no adverse effect on the tested polymers, protocol 2 was not conserved. Indeed, debris and organic matter were already observed after the digestion step (Llarena-Reino et al., 2013) and could have been problematic for experiment 3, particularly with clogging issues. Protocol 2 was consequently not retained for further investigation. Protocols $3 \& 4$ both used nitric acid and led to poor results regarding plastic integrity. The main observations that stand out after digestion with protocol 3 were: (i) the degradation of PA-12 (Fig. 1a, b), accompanied by a decrease in particle weight; and (ii) marked sample yellowing (Fig. 1c, d) observed for all polymers. Identical modifications were also observed for plastics subjected to protocol 4, though to a lesser extent, probably due to the dilution of $\mathrm{HNO}_{3}$ by one volume of $\mathrm{HClO}_{4}$. Similarly, Claessens et al. (2013) observed a critical melting of PS particles directly exposed to $\mathrm{HNO}_{3}$, although this was not observed when particles were embedded in tissues, suggesting the importance of the amount of acid directly in contact with plastics. The present study confirms previous findings of polyamide degradation (Claessens et al., 2013; OSPAR, 2015). Such a result is a major concern, as this plastic family represents a significant volume of production worldwide, and may thus be found in the environment with an increased likelihood (Dantas et al., 2012; Lusher et al., 2013; Rochman et al., 2015). Therefore, the use of $\mathrm{HNO}_{3}$ to digest seafood products for microplastic surveys should be proscribed. 
Protocols 5 and 6 did not affect the plastic polymers tested here. No modification of weight and shape was observed. Furthermore, these protocols have the additional advantages of short incubation duration (24 h) and use relatively low cost chemicals.

Based on these results, it was decided to keep protocols 5 and 6 as such, and to revise protocol 1 as suggested by Rochman et al. (2015), by reducing the incubation time to $24 \mathrm{~h}$ and increasing the incubation temperature to $60^{\circ} \mathrm{C}$ (Protocol 1b).

\subsection{Experiment 2: impact of the three selected digestion protocols on the integrity of $\mathbf{1 5}$} plastic families

Protocols $1 \mathrm{~b}, 5$ and 6 were tested on a wide range of 15 plastic families (1-5 mm), using microscopic observation, precision weighings, Raman micro-spectrometry and Pyr-GC/MS identifications.

\subsubsection{Change in weights}

The majority of plastics appeared not to be affected by the application of protocols $1 \mathrm{~b}, 5$ and 6 , with no significant changes in weight for the three replicates of respectively 10, 11 and 10 families (Table 1; Supplemental Fig. 1, $2 \&$ 3). Regardless of the tested protocol, ePS masses were too close to the quantification limit of the analytical balance, with weights lower than $0.1 \mathrm{mg}$. This was not surprising considering that expanded polystyrene mainly contains air. Thus, weighing was not conclusive for ePS, and impacts of the protocols on sample integrities were exclusively evaluated by microscopic observations, Pyr-GC/MS and Raman spectroscopy analyses.

Regarding protocols $1 \mathrm{~b}$ and 6, incoherent weight increase/decrease were observed for one out of the three replicates of respectively HDPE, PC and PP and with PA-6, PMMA and PTFE, as illustrated for PC in Fig. 2. Microscopic inspections of fragments did not show any variation suggesting these results could not be considered as representative of the overall trend for each of these families. This emphasized the need of a strict control by microscopy, as performed in this study, when assessing impact of protocols on microplastics integrity. 
322 A single family of plastic, CA, was substantially degraded by each of the three protocols (Fig. 2). The 323 mass reduction was close to $50 \%$ with protocol 1 b (Fig. 2a), and was even more pronounced with 324 protocol 5 (Fig. 2b) and 6 (Fig. 2c). For the latter, the degradation of the plastic was almost total with a 325 drop in weight to below the limit of quantification by the analytical balance.

326 Protocol 5 led to the degradation of two additional plastics: PC and PET (Fig. 2b). The case of PC is especially obvious with a complete dissolution of the plastic during the post-protocol flushing. The decrease recorded for PET was less drastic but still large, around 50\%.

\subsubsection{Microscopic inspection}

All protocols led to a marked modification of CA fragment sizes and shapes (Fig. 3). Decrease in size was particularly important and comprised between 64 and $67 \%$ for protocol 5 and between 69 and 95\% for protocol 6. A noticeable opacification of CA was observed with protocol 1 and apparitions of streaks were observed with protocols 5 and 6 (Fig. 3).

The weight changes described for PET and PC after application of protocol 5 were confirmed by visual inspection (Fig. 3), where a marked decrease of fragment size (53-60\%) was observed together with the apparition of streaks on PET, and a complete dissolution of PC during the post-protocol flushing (Fig. 3). Before this decomposition, the colour of PC was yellow/brown.

No substantial modification of plastic shapes and sizes was recorded with protocol $1 \mathrm{~b}, 5$ and 6 for all the other plastic families, corresponding respectively to 14,12 and 14 types of the 15 tested polymers.

\subsubsection{Plastic identification}

341 Regardless of which protocol was applied, it is noteworthy to mention that the Pyr-GC/MS and Raman 342 micro-spectrometry methods allowed the identification of the native molecule for PE and PS, but it 343 remained difficult to establish differences between the subtype of polymers, i.e. LDPE vs. HDPE or ePS vs. PS vs. PSXL. 
345 For all protocols a large majority of plastic were correctly identified by Pyr-GC/MS after application of 346 digestion procedures with pyrogram similarities higher than $80 \%$. This is the case for 14 families with 347 protocol $1 \mathrm{~b}, 13$ with protocol 5, and 14 families with protocol 6 (Table 1). CA identification was 348 problematic after application of protocols $1 \mathrm{~b}$ and 5 . Inaccurate identification and similarity to the 349 pyrogram for "wood powder" were probably due to the digestion of CA. Indeed, wood powder is rich in 350 cellulose that is also a major compound of CA. However, despite being clearly degraded by protocol 6, 351 CA was well identified by Pyr-GC/MS suggesting that the mass decrease had no incidence on the 352 molecule structure. Similarly, despite a clear degradation of PET by protocol 5, identification by Pyr353 GC/MS was not affected. Finally, PC and PUR respectively treated with protocol 5 and 6 were not 354 accurately identified. These results could be explained respectively by the fact that PC was completely dissolved by $10 \mathrm{M} \mathrm{NaOH}$, and by an adverse impact of peroxodisulfate on PUR identification.

Results of the Raman micro-spectroscopy analysis showed modifications of spectra intensities for all treatments compared with untreated reference materials (Fig. 4). These variations of intensity are mainly due to the location of the impact point of the laser on the surface of the analysed polymer despite a focus adjustment before each acquisition. The heterogeneity of the particle in terms of morphology, roughness or orientation and the move of particles before and after chemical treatments conduct to intensity fluctuations (Lenz et al., 2015). It is however not excluded that these modifications of intensity could also be due to polymer molecular alteration after the chemical treatments (Collard et al., 2015). But, in this case, band shifts would also have been expected. On contrary, chemical treatments did not affect

364 polymer successful identification (Table 1), except for CA where the spectral fingerprints changed after treatment by $\mathrm{NaOH}$ and $\mathrm{KOH}$, suggesting a modification of the molecular structure. Moreover, the spectrum quality of CA was impacted by a strong fluorescence with the $\mathrm{KOH}$ treatment, affecting its identification. No effect was observed on the spectra of any polymer families after digestion with peroxodisulfate. 
Protocol $1 \mathrm{~b}\left(10 \% \mathrm{KOH}, 24 \mathrm{~h}, 60^{\circ} \mathrm{C}\right)$ appeared to be the most promising protocol in our experiments in terms of absence of substantial degradation of the plastic polymers tested here. It is noteworthy that the impacts of this protocol on the 15 plastic polymer families were further assessed under agitation ( 300 rpm), to match the optimal conditions for biological tissue digestion (see below), and similar results were obtained, i.e. no detrimental effect on plastics (except for CA). While resistance of plastic particles subjected to $\mathrm{KOH} 10 \%$ was mentioned as "unpublished data" in Foekema et al. (2013), no detailed information was available in the literature to confirm the absence of detrimental effects on a wide range of plastic polymers and on their identification. Only CA was degraded by protocol $1 \mathrm{~b}$, yet in a lesser extent than by protocol 5 and 6 , without this being detrimental. Indeed, if CA is the main macroplastic found on coastlines (Andrady, 2015), it is a polymer derived from cellulose, a natural polymer. This property confers a good potential for environmental degradation (Puls et al., 2011) which would explain the fact that it is not recovered in marine organisms or environmental studies. The use of cellulose acetate filter should be proscribed with this method, to avoid contamination as already reported with other methods (Collard et al., 2015).

Protocol $5\left(10 \mathrm{M} \mathrm{NaOH} 60^{\circ} \mathrm{C}, 24 \mathrm{~h}\right)$ appears to be less promising than protocol $1 \mathrm{~b}$, since three plastics were degraded by the use of $10 \mathrm{M} \mathrm{NaOH}$. Contrary to previous observations (Cole et al., 2014) neither degradation of nylon (PA-6 and PA-12), even when the protocol was tested directly on nylon fibres (Supplemental Fig. 4), nor uPVC yellowing was reported in the present study. Yet worryingly, protocol 5 degraded PET, which is one of the main components of plastic beverage bottles often recovered in the marine environment (Andrady, 2015), and which ranks among the "big six", with a production estimated at more than 3 million tons in 2014 (PlasticsEurope, 2015). A decrease in peak intensity in Raman microscopy was also observed, leading to poor identification compared with protocol $1 \mathrm{~b}$. As a consequence, protocol 5 was dismissed due to the degradation of three types of polymers. degradation, along with some technical concerns related to the difficulty to prevent crystallisation of the 
peroxodisulfate in solution, and its relative cost. However, in order to evaluate its efficiency in successfully digesting the flesh of seafood, this protocol was retained for experiment 3 .

\subsection{Experiment 3: application of selected digestion protocols on seafood products}

Protocol $1 \mathrm{~b}$ using $\mathrm{KOH}$ led to a good digestion of mussel tissues, i.e. no remaining particles were visible in the digestate, which consequently allowed a good filtration on the GF/A $1.6 \mu \mathrm{m}$ fibre glass filters (Table 2; Supplemental Fig. 5). A close observation using a binocular microscope revealed a negligible amount of debris, allowing good observation and detection of microplastics (Supplemental Fig. 5). Conversely, following protocol 6, rough fragments were still observed to be present; mussel hepatopancreas remained completely undamaged (Table 2; Supplemental Fig. 5). These observations on filters were confirmed by evaluations of digestion efficiencies (Fig. 5). Efficiency was higher for protocol $1 \mathrm{~b}$ with $\%$ De ranging from 99.6 - $99.8 \%$ compared to $\% D e$ with protocol 6 ranging between 98.2 and $99.7 \%$. Consequently, filtration of the digestate subjected to protocol 6 on GF/A $1.6 \mu$ m glass fibre filters was difficult and led to a rapid clogging of the filters that inevitably ended up heavily loaded. The presence of rough organic or inorganic debris, tissues and even organs (hepatopancreas) recovered after digestion prevents the accurate detection of plastic debris in bivalves. As a consequence, protocol 6 was considered unsuitable for microplastic extraction from biological matrices, and was thus excluded from further analyses with crustacean and fish. It should also be noted that further experiments demonstrated that $\% D e$ was not affected after reduction of both volume of digestion solution $(100 \mathrm{~mL})$ and stirring speed (200 rpm) when using the protocol $1 \mathrm{~b}$ (Supplemental Fig. 6).

For crab tissues, fish fillets and whole alimentary tract, the only tested method was protocol $1 \mathrm{~b}$. It led to a very efficient digestion of crab tissues; and easy filtration and detailed observations of the filters for microplastic detection (Table 2; Supplemental Fig. 7). The presence of pieces of cartilage was not problematic as a careful rinse was performed. Fish filet were efficiently digested and the filtration on one to two GF/A $1.6 \mu \mathrm{m}$ glass fibre filters was successful. However, the fish bones must be carefully removed prior to digestion to prevent their partial dissolution leading to a high quantity of bone fragments ending up on the filters (Supplemental Fig. 8). Several filters may be needed due to the higher 
mass of tissues digested and the presence of a thin layer of grease observed on the edges of the Petri dish that may lead to some difficulties in accurately detecting microplastics if they are located below this layer (Supplemental Fig. 8). Direct filtration of the whole alimentary tract digestate was impossible because of the presence of inorganic debris present in black bream alimentary tracts collected in the Bay of Brest (France) that remained intact after digestion (data not shown). These debris consisted mainly of mærl and sand, present in large quantities in the Bay of Brest (Potin et al., 1990); therefore a slightly modified protocol using a sodium tungstate solution $\left(1.5 \mathrm{~g} / \mathrm{cm}^{3}\right)$ was tested. This allows the recovery of all plastic particles, including the densest of the "big six": PVC $\left(1.38 \mathrm{~g} / \mathrm{cm}^{3}\right)$ or PET $\left(1.37 \mathrm{~g} / \mathrm{cm}^{3}\right)$ (Andrady, 2015); without filtration of the high load of inorganic particles. It is noteworthy to mention that this density-based separation step should be suitable for sediment dwelling molluscs and crustaceans that may exhibit high coarse sediment contents in their digestive tracts. Due to this additional step, the filtration and the filter observation were much easier (Supplemental Fig. 8), allowing a good detection of microplastic-like particles.

Finally an integrated approach was performed using protocol $1 \mathrm{~b}$, the digestion of the different spiked samples of seafood tissues led to excellent recovery and no impact of protocol $1 \mathrm{~b}$ was observed on the integrity of particles. Recovery percentages were of $100 \%$ for cod fillets, saithe whole alimentary tracts and mussels. It should also be mentioned that digestion process did not affect identification of the nylon particles spiked in fillets, whose pyrograms displayed $93 \%$ of similarity with the one of PA-6.

\section{Conclusion}

440 In conclusion, the protocol using $\mathrm{KOH} 10 \%$ solution with incubation at $60{ }^{\circ} \mathrm{C}$ for $24 \mathrm{~h}$ overcame current

441 methodological barriers and was proposed as a good compromise for extraction and characterization of 442 microplastics from seafood tissues. This protocol appears to be the best compromise and should be implemented for further studies to assure the relevance and comparison of environmental studies, notably following OSPAR and Marine Strategy Framework Directive recommendation, as well as for 
seafood product quality. Mollusc, crustacean, and fish were tested, suggesting the broad usefulness of this protocol on aquatic species.

447 Based on the present work, the use of nitric acid is not recommended for the study of microplastics because of its degrading action on polyamide and its tendency to yellow plastics. An approach using enzymatic digestion was discarded because of the difficulty in its implementation and digestion efficacy issues. The use of oxidizing solution was promising, with almost no deleterious consequence on plastics, but application to seafood products led to incomplete digestion of mussel tissues. The $\mathrm{NaOH}$ solution resulted in adverse destructive effects on integrity of three plastics (CA, PC and PET), thus its use is not recommended here.

\section{Acknowledgments}

Authors warmly thank Mélanie Gay and Régine Quenu for their valued help with metrology issues, Marie-Ange Huchin and Mr. Bourdin for their kind technical assistance. This work was funded by ANSES (French Agency for Food, Environmental and Occupational Health \& Safety) through a "Convention de Recherche et Développement". Laura Frère was supported by a Université de Bretagne Occidentale and a Brest Métropole PhD grant. Ludovic Hermabessiere is thankful to Région Nord-Pasde-Calais and ANSES for the financial support of his PhD. Authors also thank Dr. E. Harney for his helpful revision of the English and his comments on the manuscript.

\section{References}

Andrady, A.L., 2015. Persistence of Plastic Litter in the Oceans, in: Bergmann, M., Gutow, L., Klages, M. (Eds.), Marine Anthropogenic Litter. Springer International Publishing, Cham, pp. 57-72.

Arthur, C., Baker, J., Bamford, H., 2009. Proceedings of the International Research Workshop on the Occurance, Effects, and Fate of Mircroplastic Marine Debris. Dep. Commer. Natl. Ocean. Atmospheric Adm. Tech. Memo. NOS-ORR-30.

Avio, C.G., Gorbi, S., Regoli, F., 2015. Experimental development of a new protocol for extraction and characterization of microplastics in fish tissues: First observations in commercial species from Adriatic Sea. Mar. Environ. Res., Particles in the Oceans: Implication for a safe marine environment 111, 18-26. doi:10.1016/j.marenvres.2015.06.014

Boerger, C.M., Lattin, G.L., Moore, S.L., Moore, C.J., 2010. Plastic ingestion by planktivorous fishes in the North Pacific Central Gyre. Mar. Pollut. Bull. 60, 2275-2278. doi:10.1016/j.marpolbul.2010.08.007 
Browne, M.A., Galloway, T., Thompson, R., 2007. Microplastic-an emerging contaminant of potential concern? Integr. Environ. Assess. Manag. 3, 559-561. doi:10.1002/ieam.5630030412

Browne, M.A., Niven, S.J., Galloway, T.S., Rowland, S.J., Thompson, R.C., 2013. Microplastic Moves Pollutants and Additives to Worms, Reducing Functions Linked to Health and Biodiversity. Curr. Biol. 23, 2388-2392. doi:10.1016/j.cub.2013.10.012

Carpenter, E.J., Anderson, S.J., Harvey, G.R., Miklas, H.P., Peck, B.B., 1972. Polystyrene Spherules in Coastal Waters. Science 178, 749-750. doi:10.1126/science.178.4062.749

Chang, M., 2015. Reducing microplastics from facial exfoliating cleansers in wastewater through treatment versus consumer product decisions. Mar. Pollut. Bull. doi:10.1016/j.marpolbul.2015.10.074

Claessens, M., Van Cauwenberghe, L., Vandegehuchte, M.B., Janssen, C.R., 2013. New techniques for the detection of microplastics in sediments and field collected organisms. Mar. Pollut. Bull. 70, 227-233. doi:10.1016/j.marpolbul.2013.03.009

Codina-García, M., Militão, T., Moreno, J., González-Solís, J., 2013. Plastic debris in Mediterranean seabirds. Mar. Pollut. Bull. 77, 220-226. doi:10.1016/j.marpolbul.2013.10.002

Cole, M., Lindeque, P., Fileman, E., Halsband, C., Goodhead, R., Moger, J., Galloway, T.S., 2013. Microplastic Ingestion by Zooplankton. Environ. Sci. Technol. 130606145528005. doi:10.1021/es400663f

Cole, M., Lindeque, P., Halsband, C., Galloway, T.S., 2011. Microplastics as contaminants in the marine environment: a review. Mar. Pollut. Bull. 62, 2588-2597. doi:10.1016/j.marpolbul.2011.09.025

Cole, M., Webb, H., Lindeque, P.K., Fileman, E.S., Halsband, C., Galloway, T.S., 2014. Isolation of microplastics in biota-rich seawater samples and marine organisms. Sci Rep 4, 4528. doi:10.1038/srep04528

Collard, F., Gilbert, B., Eppe, G., Parmentier, E., Das, K., 2015. Detection of Anthropogenic Particles in Fish Stomachs: An Isolation Method Adapted to Identification by Raman Spectroscopy. Arch. Environ. Contam. Toxicol. 69, 331-339. doi:10.1007/s00244-015-0221-0

Corcoran, P.L., Biesinger, M.C., Grifi, M., 2009. Plastics and beaches: A degrading relationship. Mar. Pollut. Bull. 58, 80-84. doi:10.1016/j.marpolbul.2008.08.022

Cozar, A., Echevarria, F., Gonzalez-Gordillo, J.I., Irigoien, X., Ubeda, B., Hernandez-Leon, S., Palma, A.T., Navarro, S., Garcia-de-Lomas, J., Ruiz, A., Fernandez-de-Puelles, M.L., Duarte, C.M., 2014. Plastic debris in the open ocean. Proc. Natl. Acad. Sci. 111, 10239-10244. doi:10.1073/pnas.1314705111

Dantas, D.V., Barletta, M., da Costa, M.F., 2012. The seasonal and spatial patterns of ingestion of polyfilament nylon fragments by estuarine drums (Sciaenidae). Environ. Sci. Pollut. Res. 19, 600-606. doi:10.1007/s11356-011-0579-0

De Witte, B., Devriese, L., Bekaert, K., Hoffman, S., Vandermeersch, G., Cooreman, K., Robbens, J., 2014. Quality assessment of the blue mussel (Mytilus edulis): Comparison between commercial and wild types. Mar. Pollut. Bull. 85, 146-155. doi:10.1016/j.marpolbul.2014.06.006

Eriksen, M., Lebreton, L.C.M., Carson, H.S., Thiel, M., Moore, C.J., Borerro, J.C., Galgani, F., Ryan, P.G., Reisser, J., 2014. Plastic Pollution in the World's Oceans: More than 5 Trillion Plastic Pieces Weighing over 250,000 Tons Afloat at Sea. PLoS ONE 9, e111913. doi:10.1371/journal.pone.0111913

European Commission, 2010. Commission decision of 1 September 2010 on criteria and methodological standards on good environmental status of marine waters (notified under document C(2010) 5956) 2010/477/EU, 1424.

Farrell, P., Nelson, K., 2013. Trophic level transfer of microplastic: Mytilus edulis (L.) to Carcinus maenas (L.). Environ. Pollut. 177, 1-3. doi:10.1016/j.envpol.2013.01.046

Fischer, V., Elsner, N.O., Brenke, N., Schwabe, E., Brandt, A., 2015. Plastic pollution of the Kuril-Kamchatka Trench area (NW pacific). Deep Sea Res. Part II Top. Stud. Oceanogr. 111, 399-405. doi:10.1016/j.dsr2.2014.08.012

Foekema, E.M., De Gruijter, C., Mergia, M.T., van Franeker, J.A., Murk, A.J., Koelmans, A.A., 2013. Plastic in north sea fish. Env. Sci Technol 47, 8818-24. doi:10.1021/es400931b 
Fries, E., Dekiff, J.H., Willmeyer, J., Nuelle, M.-T., Ebert, M., Remy, D., 2013. Identification of polymer types and additives in marine microplastic particles using pyrolysis-GC/MS and scanning electron microscopy. Environ. Sci. Process. Impacts 15, 1949. doi:10.1039/c3em00214d

ISO/IEC Guide 98-3, 2008. Uncertainty of measurement -- Part 3: Guide to the expression of uncertainty in measurement (GUM:1995) 130.

Karl, H., Ostermeyer, U., Bauer, H., Miller, A., Mohn, K., Müller-Hohe, E., Neuhaus, H., Pölzelbauer, C., Stumme, B., Walter, M., 2014. Collaborative study for quantification of Anisakis larvae in spiked salmon fillets (Salmo salar) by a modified Codex digestion method. J. Für Verbraucherschutz Leb. 9, 359-365. doi:10.1007/s00003-014-0907-7

Laist, D.W., 1987. Overview of the biological effects of lost and discarded plastic debris in the marine environment. Mar. Pollut. Bull. 18, 319-326. doi:10.1016/S0025-326X(87)80019-X

Lattin, G.L., Moore, C.J., Zellers, A.F., Moore, S.L., Weisberg, S.B., 2004. A comparison of neustonic plastic and zooplankton at different depths near the southern California shore. Mar. Pollut. Bull. 49, 291-294. doi:10.1016/j.marpolbul.2004.01.020

Lenz, R., Enders, K., Stedmon, C.A., Mackenzie, D.M.A., Nielsen, T.G., 2015. A critical assessment of visual identification of marine microplastic using Raman spectroscopy for analysis improvement. Mar. Pollut. Bull. 100, 82-91. doi:10.1016/j.marpolbul.2015.09.026

Llarena-Reino, M., Piñeiro, C., Antonio, J., Outeriño, L., Vello, C., González, Á.F., Pascual, S., 2013. Optimization of the pepsin digestion method for anisakids inspection in the fishing industry. Vet. Parasitol. 191, 276-283. doi:10.1016/j.vetpar.2012.09.015

Lusher, A., 2015. Microplastics in the Marine Environment: Distribution, Interactions and Effects 245-307. doi:10.1007/978-3-319-16510-3_10

Lusher, A.L., Burke, A., O’Connor, I., Officer, R., 2014. Microplastic pollution in the Northeast Atlantic Ocean: Validated and opportunistic sampling. Mar. Pollut. Bull. 88, 325-333. doi:10.1016/j.marpolbul.2014.08.023

Lusher, A.L., Hernandez-Milian, G., O’Brien, J., Berrow, S., O’Connor, I., Officer, R., 2015. Microplastic and macroplastic ingestion by a deep diving, oceanic cetacean: The True's beaked whale Mesoplodon mirus. Environ. Pollut. 199, 185-191. doi:10.1016/j.envpol.2015.01.023

Lusher, A.L., McHugh, M., Thompson, R.C., 2013. Occurrence of microplastics in the gastrointestinal tract of pelagic and demersal fish from the English Channel. Mar. Pollut. Bull. 67, 94-99. doi:10.1016/j.marpolbul.2012.11.028

Maher, W., Krikowa, F., Wruck, D., Louie, H., Nguyen, T., Huang, W., 2002. Determination of total phosphorus and nitrogen in turbid waters by oxidation with alkaline potassium peroxodisulfate and low pressure microwave digestion, autoclave heating or the use of closed vessels in a hot water bath: comparison with Kjeldahl digestion. Anal. Chim. Acta 463, 283-293. doi:10.1016/S0003-2670(02)00346-X

Mato, Y., Isobe, T., Takada, H., Kanehiro, H., Ohtake, C., Kaminuma, T., 2001. Plastic Resin Pellets as a Transport Medium for Toxic Chemicals in the Marine Environment. Environ. Sci. Technol. 35, 318-324. doi:10.1021/es0010498

Moore, C.J., 2008. Synthetic polymers in the marine environment: A rapidly increasing, long-term threat. Plast. World 108, 131-139. doi:10.1016/j.envres.2008.07.025

Moore, C.., Moore, S.., Leecaster, M.., Weisberg, S.., 2001. A Comparison of Plastic and Plankton in the North Pacific Central Gyre. Mar. Pollut. Bull. 42, 1297-1300. doi:10.1016/S0025-326X(01)00114-X

Napper, I.E., Bakir, A., Rowland, S.J., Thompson, R.C., 2015. Characterisation, quantity and sorptive properties of microplastics extracted from cosmetics. Mar. Pollut. Bull. 99, 178-185. doi:10.1016/j.marpolbul.2015.07.029

Nuelle, M.-T., Dekiff, J.H., Remy, D., Fries, E., 2014. A new analytical approach for monitoring microplastics in marine sediments. Environ. Pollut. 184, 161-169. doi:10.1016/j.envpol.2013.07.027

OSPAR, 2015. OSPAR request on development of a common monitoring protocol for plastic particles in fish stomachs and selected shellfish on the basis of existing fish disease surveys. ICES Advice 2015 - Book 1 1-6.

PlasticsEurope, 2015. Plastics - the Facts 2015: An analysis of European plastics production, demand and waste data. 
Potin, P., Floc'h, J.Y., Augris, C., Cabioch, J., 1990. Annual growth rate of the calcareous red alga Lithothamnion corallioides (Corallinales, Rhodophyta) in the Bay of Brest, France. Hydrobiologia 204-205, 263-267. doi:10.1007/BF00040243

Puls, J., Wilson, S.A., Hölter, D., 2011. Degradation of Cellulose Acetate-Based Materials: A Review. J. Polym. Environ. 19, 152-165. doi:10.1007/s10924-010-0258-0

Rochman, C.M., Tahir, A., Williams, S.L., Baxa, D.V., Lam, R., Miller, J.T., Teh, F.-C., Werorilangi, S., Teh, S.J., 2015. Anthropogenic debris in seafood: Plastic debris and fibers from textiles in fish and bivalves sold for human consumption. Sci. Rep. 5, 14340. doi:10.1038/srep14340

Setälä, O., Fleming-Lehtinen, V., Lehtiniemi, M., 2014. Ingestion and transfer of microplastics in the planktonic food web. Environ. Pollut. 185, 77-83. doi:10.1016/j.envpol.2013.10.013

Shah, A.A., Hasan, F., Hameed, A., Ahmed, S., 2008. Biological degradation of plastics: A comprehensive review. Biotechnol. Adv. 26, 246-265. doi:10.1016/j.biotechadv.2007.12.005

Shim, W.J., Thompson, R.C., 2015. Microplastics in the Ocean. Arch. Environ. Contam. Toxicol. 69, 265-268. doi:10.1007/s00244-015-0216-x

Sussarellu, R., Suquet, M., Thomas, Y., Lambert, C., Fabioux, C., Pernet, M.E.J., Le Goïc, N., Quillien, V., Mingant, C., Epelboin, Y., Corporeau, C., Guyomarch, J., Robbens, J., Paul-Pont, I., Soudant, P., Huvet, A., 2016. Oyster reproduction is affected by exposure to polystyrene microplastics. Proc. Natl. Acad. Sci. 201519019. doi:10.1073/pnas.1519019113

Teuten, E.L., Saquing, J.M., Knappe, D.R.U., Barlaz, M.A., Jonsson, S., Bjorn, A., Rowland, S.J., Thompson, R.C., Galloway, T.S., Yamashita, R., Ochi, D., Watanuki, Y., Moore, C., Viet, P.H., Tana, T.S., Prudente, M., Boonyatumanond, R., Zakaria, M.P., Akkhavong, K., Ogata, Y., Hirai, H., Iwasa, S., Mizukawa, K., Hagino, Y., Imamura, A., Saha, M., Takada, H., 2009. Transport and release of chemicals from plastics to the environment and to wildlife. Philos. Trans. R. Soc. B Biol. Sci. 364, 2027-2045. doi:10.1098/rstb.2008.0284

Thompson, R.C., 2006. Plastic debris in the marine environment: consequences and solutions. Mar. Nat. Conserv. Eur. 2006 107-115.

Thompson, R.C., 2004. Lost at Sea: Where Is All the Plastic? Science 304, 838-838. doi:10.1126/science.1094559

Tourinho, P.S., Ivar do Sul, J.A., Fillmann, G., 2010. Is marine debris ingestion still a problem for the coastal marine biota of southern Brazil? Mar. Pollut. Bull. 60, 396-401. doi:10.1016/j.marpolbul.2009.10.013

Van Cauwenberghe, L., Claessens, M., Vandegehuchte, M.B., Janssen, C.R., 2015. Microplastics are taken up by mussels (Mytilus edulis) and lugworms (Arenicola marina) living in natural habitats. Environ. Pollut. 199, 10-17. doi:10.1016/j.envpol.2015.01.008

Van Cauwenberghe, L., Janssen, C.R., 2014. Microplastics in bivalves cultured for human consumption. Environ. Pollut. 193, 65-70. doi:10.1016/j.envpol.2014.06.010

Van Cauwenberghe, L., Vanreusel, A., Mees, J., Janssen, C.R., 2013. Microplastic pollution in deep-sea sediments. Environ. Pollut. 182, 495-499. doi:10.1016/j.envpol.2013.08.013

van Wezel, A., Caris, I., Kools, S., 2015. Release of primary microplastics from consumer products to wastewater in The Netherlands. Environ. Toxicol. Chem. SETAC. doi:10.1002/etc.3316

Watts, A.J.R., Lewis, C., Goodhead, R.M., Beckett, S.J., Moger, J., Tyler, C.R., Galloway, T.S., 2014. Uptake and Retention of Microplastics by the Shore Crab Carcinus maenas. Environ. Sci. Technol. 48, 8823-8830. doi:10.1021/es501090e

Zettler, E.R., Mincer, T.J., Amaral-Zettler, L.A., 2013. Life in the "Plastisphere": Microbial Communities on Plastic Marine Debris. Environ. Sci. Technol. 130619162220002. doi:10.1021/es401288x 
614 Figure 1. Microscopic observations of plastics treated with protocol $3\left(65 \% \mathrm{HNO}_{3}\right.$ at room temperature 615 overnight, then $60^{\circ} \mathrm{C}$ for $2 \mathrm{~h}$ ). On the upper half: pictures of polylauryllactam (PA-12) before (a) and 616 after (b) application of protocol. On the lower half: pictures of low density polyethylene (LDPE) before 617 (c) and after (d) application of the protocol.

618 Figure 2. Bar chart representing evolution of weight (mg) for cellulose acetate (CA), polycarbonate 619 (PC) and polyethylene terephthalate (PET) before and after application of protocol 1b, 10\% KOH, $24 \mathrm{~h}$, $62060^{\circ} \mathrm{C}$ (a), protocol 5, $10 \mathrm{M} \mathrm{NaOH} 60^{\circ} \mathrm{C}, 24 \mathrm{~h}\left(\right.$ b) and protocol $6 \mathrm{~K}_{2} \mathrm{~S}_{2} \mathrm{O}_{8} / \mathrm{NaOH} 65^{\circ} \mathrm{C}, 24 \mathrm{~h}(\mathrm{c})$. White and dark grey bars represent the mean of 5 repeated weight measures of three plastic samples (S1, S2 \& S3) respectively before and after application of protocols. Error bars on charts represent the expanded weighing uncertainty of the results $U_{e b}$ (see 2.1).

Figure 3. Pictures of the three types of polymers; cellulose acetate (CA), polycarbonate (PC), polyethylene terephthalate (PET) mostly affected by protocols $1 \mathrm{~b}\left(10 \% \mathrm{KOH}, 24 \mathrm{~h}, 60^{\circ} \mathrm{C}\right), 5(10 \mathrm{M}$ $\left.\mathrm{NaOH} 60^{\circ} \mathrm{C}, 24 \mathrm{~h}\right)$ and $6\left(\mathrm{~K}_{2} \mathrm{~S}_{2} \mathrm{O}_{8} / \mathrm{NaOH} 65^{\circ} \mathrm{C}, 24 \mathrm{~h}\right)$. For each protocol the picture of a single sample is presented before and after application of the protocol. White bars correspond to $1 \mathrm{~mm}$.

Figure 4. Raman spectra of the 15 polymers prior and after treatment by protocol $1 \mathrm{~b}(10 \% \mathrm{KOH}, 24 \mathrm{~h}$, $\left.60{ }^{\circ} \mathrm{C}\right), 5\left(10 \mathrm{M} \mathrm{NaOH} 60^{\circ} \mathrm{C}, 24 \mathrm{~h}\right)$ and $6\left(\mathrm{~K}_{2} \mathrm{~S}_{2} \mathrm{O}_{8} / \mathrm{NaOH} 65^{\circ} \mathrm{C}, 24 \mathrm{~h}\right)$. All spectra were normed excepted for CA spectrum treated with protocol 5 , for which a simple decrease in intensity was applied. A normed spectrum is obtained by dividing peak areas by that of the major peak. (CA: cellulose acetate; ePS: expanded polystyrene; HDPE: high density polyethylene; LDPE: low density polyethylene; PA-12: polylauryllactam; PA-6: polycaprolactam; PC: polycarbonate; PET: polyethylene terephthalate; PMMA: poly(methyl-methacrylate); PP: polypropylene; PS: polystyrene; PTFE: polytetrafluoroethylene; PUR: polyurethane; PSXL: crosslinked polystyrene; uPVC: unplasticized polyvinyl chloride).

Figure 5. Bar chart representing individual digestion efficiencies $(\% D e)(\mathrm{n}=5)$ on three mussels, $\mathrm{M} 1$ to 
$\left.638{ }^{\circ} \mathrm{C}, 24 \mathrm{~h}\right)$ in white. The very low standard deviations $(<0.01 \%)$ do not appear on bar diagrams as they 639 could not be distinctively traced. 
$640 \quad$ Figure 1
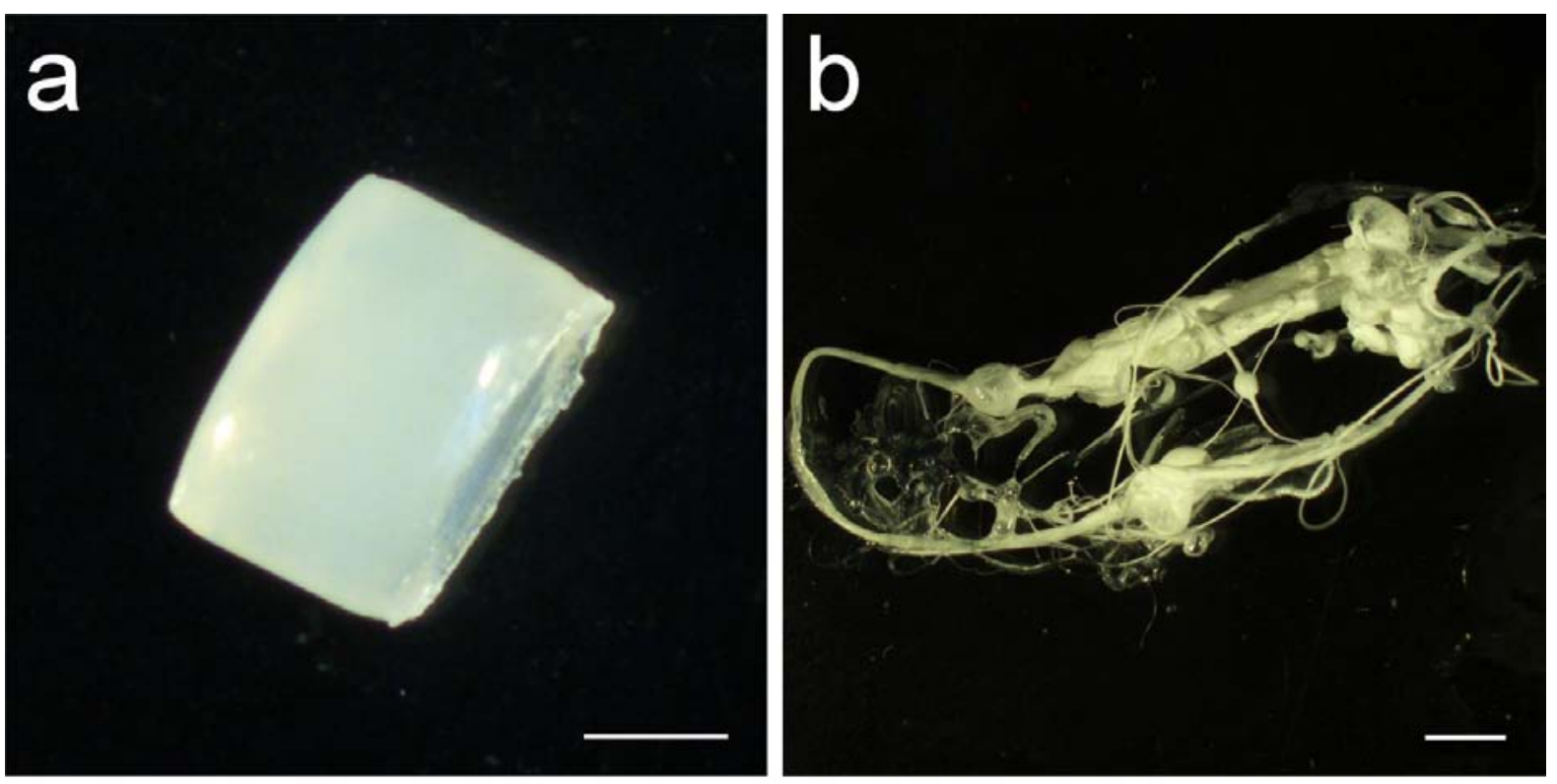

C

d

641
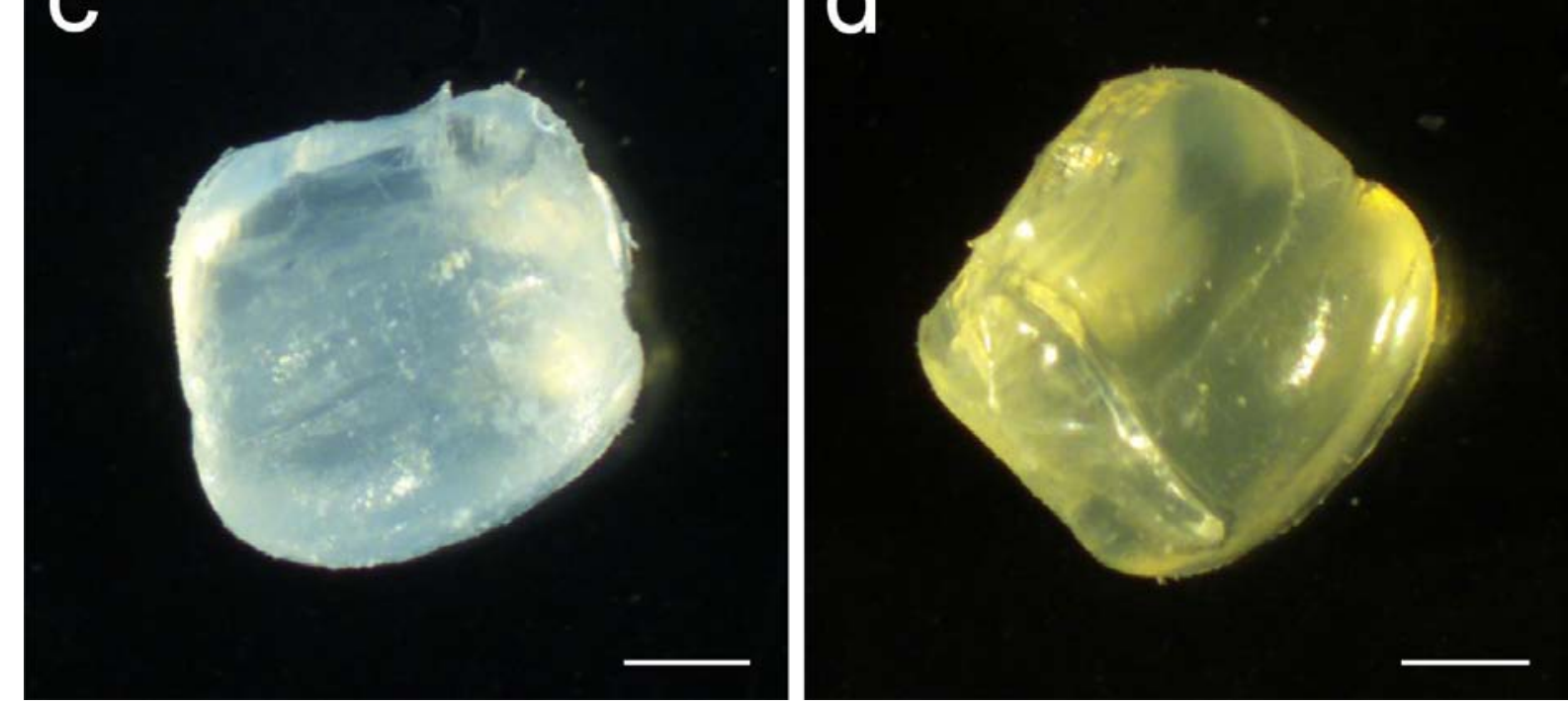
Figure 2
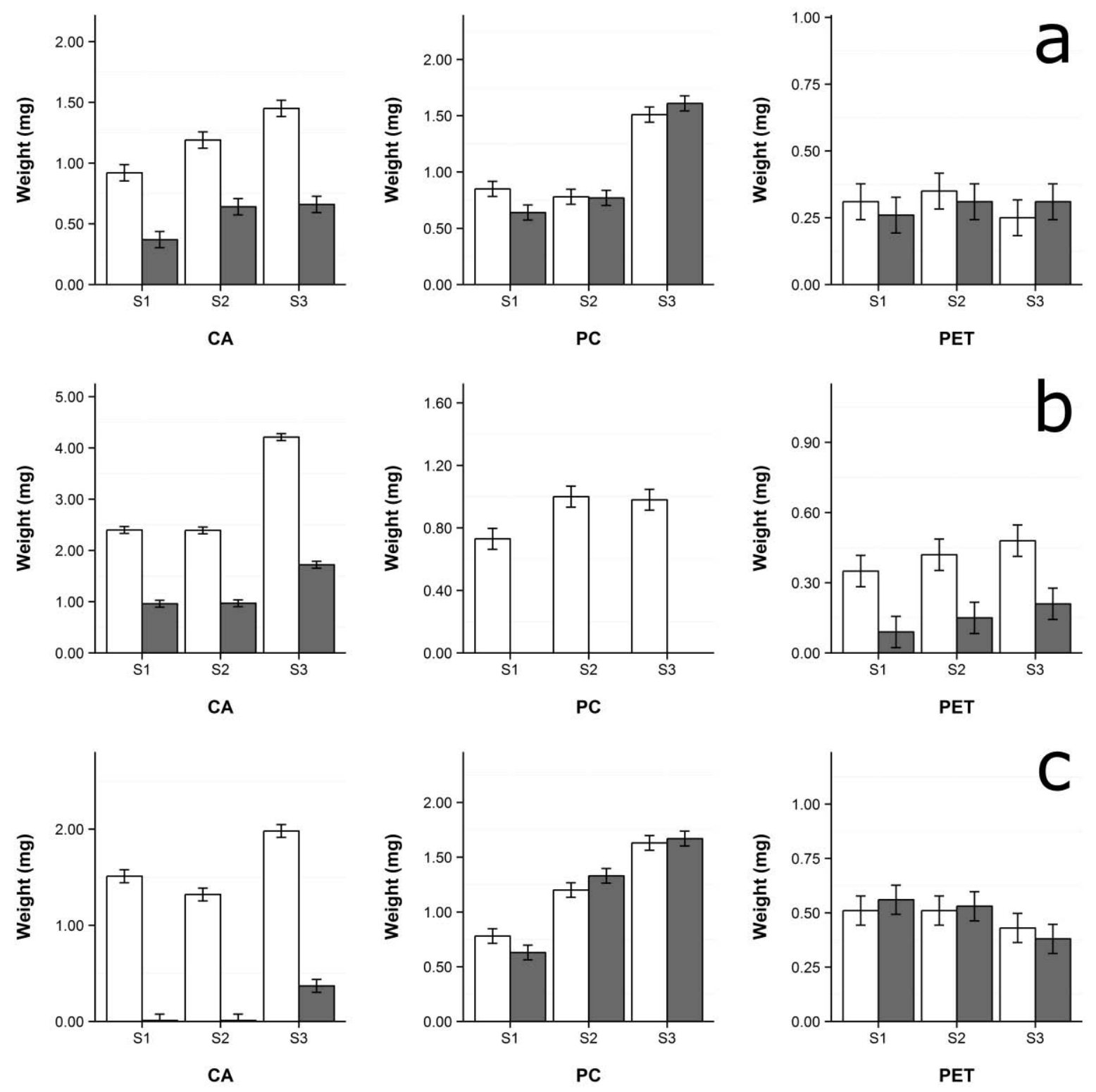


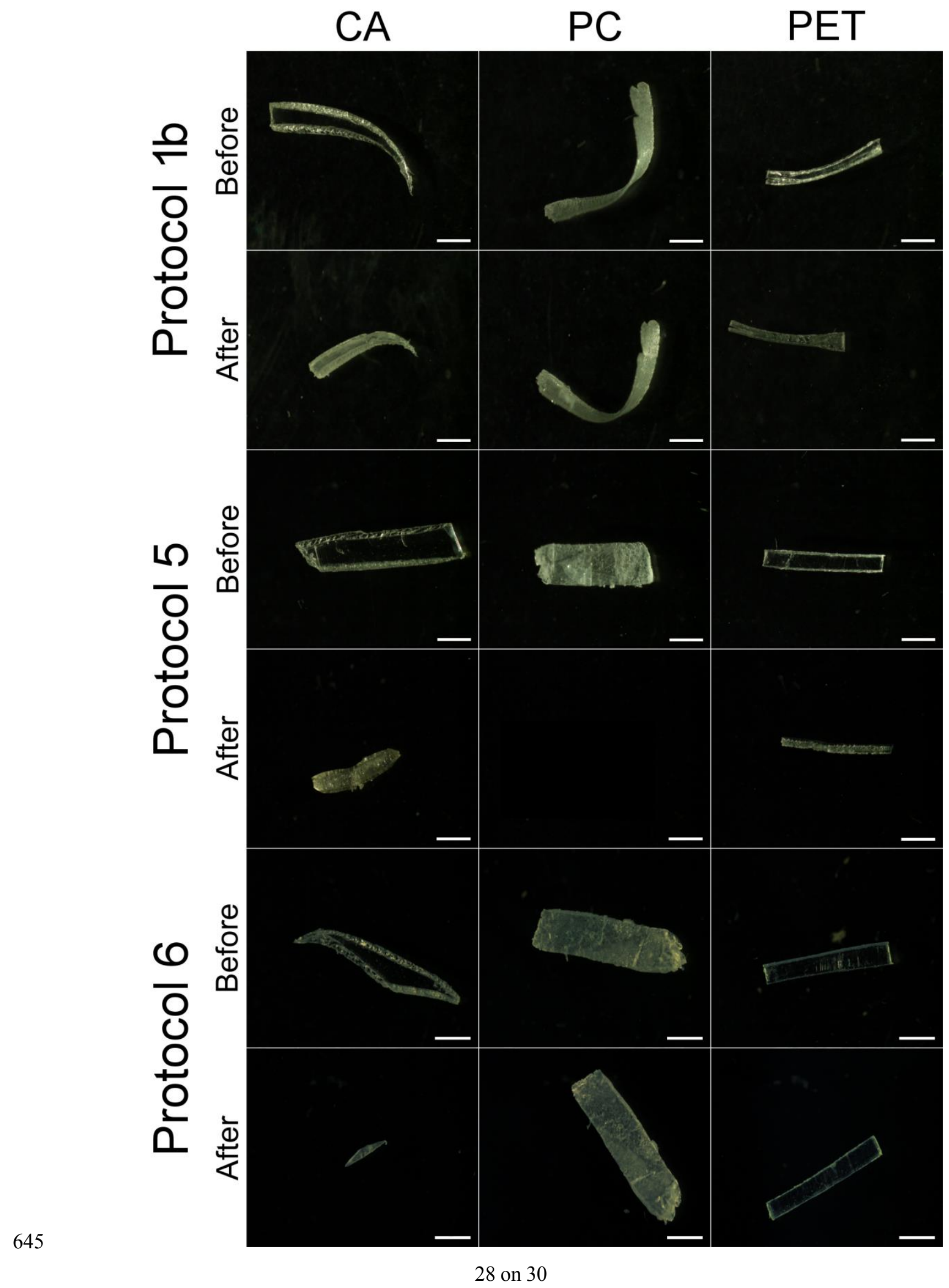




\section{Figure 4}

647
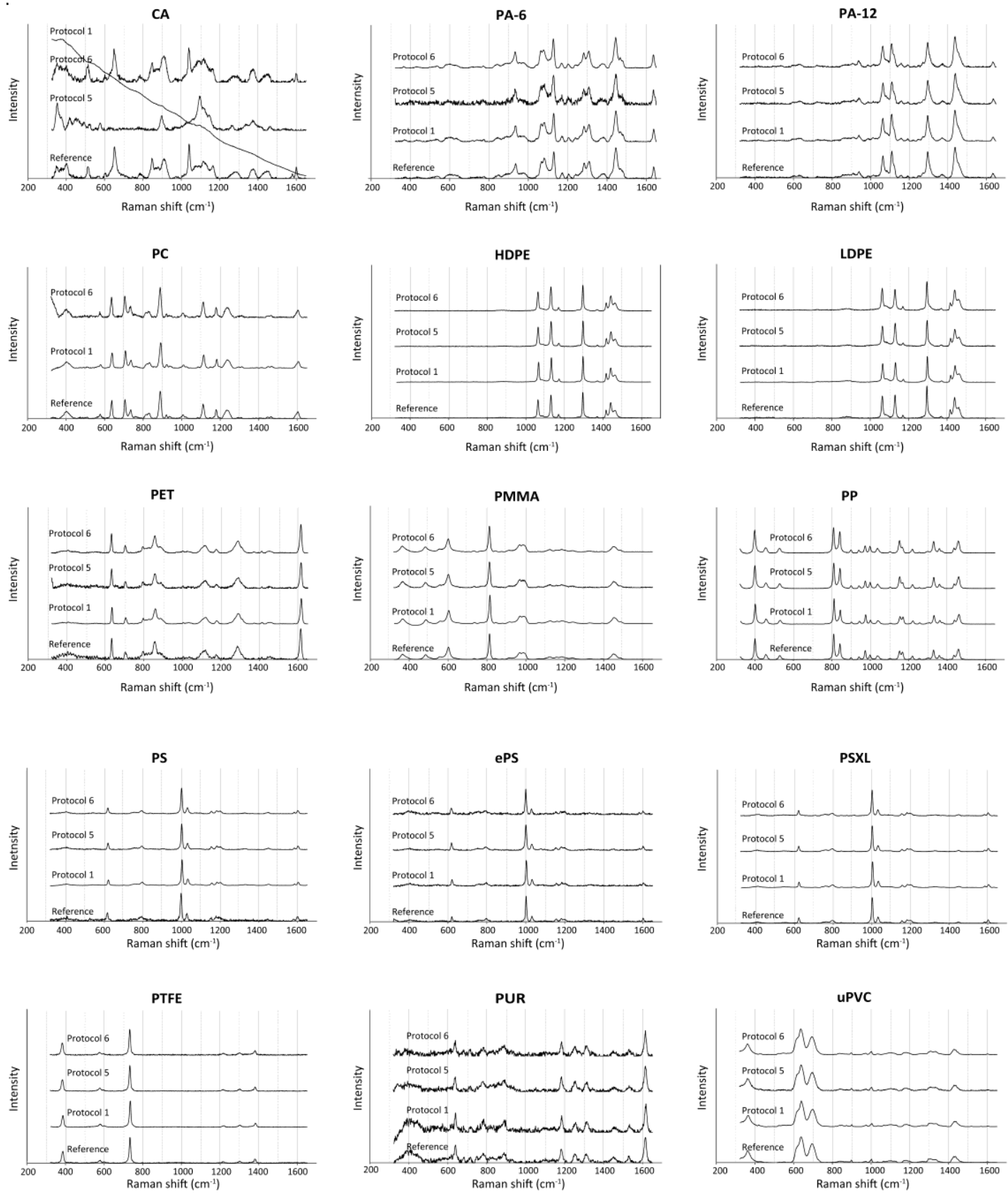
$649 \quad$ Figure 5

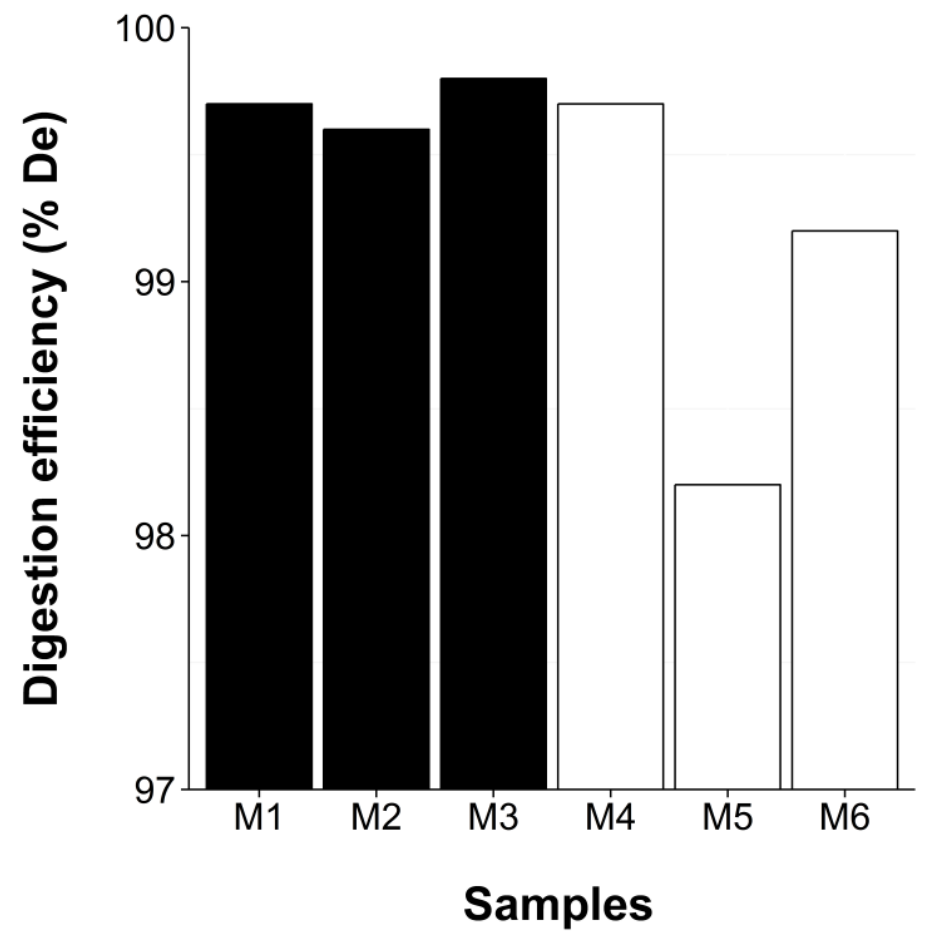

650 


\section{Tables}

Table 1

Summary of passed/unpassed analyses by plastics in experiment 2 .

\begin{tabular}{|c|c|c|c|c|c|c|c|c|c|c|c|c|c|c|c|c|}
\hline Protocols & Analyses & $\mathrm{CA}$ & ePS & HDPE & LDPE & PA-12 & PA-6 & PC & PET & PMMA & PP & PS & PTFE & PUR & PSXL & uPVC \\
\hline \multirow{4}{*}{ 1b $10 \% \mathrm{KOH}\left(60^{\circ} \mathrm{C}, 24 \mathrm{~h}\right)$} & Weighing & $x$ & NA & $\boldsymbol{J}^{*}$ & $\checkmark$ & $\checkmark$ & $\checkmark$ & $\mathfrak{l}^{*}$ & $\checkmark$ & $\checkmark$ & $\boldsymbol{J}^{*}$ & $\checkmark$ & $\checkmark$ & $\checkmark$ & $\checkmark$ & $\checkmark$ \\
\hline & Visual & $\mathrm{Sh}, \mathrm{Si}$ & $\checkmark$ & $\checkmark$ & $\checkmark$ & $\checkmark$ & $\checkmark$ & $\checkmark$ & Sh & $\checkmark$ & $\checkmark$ & $\checkmark$ & $\checkmark$ & $\checkmark$ & $\checkmark$ & $\checkmark$ \\
\hline & Pyr-GC/MS & $x$ & $\mathcal{J}^{\#}$ & $\Omega^{\#}$ & $\mathcal{J}^{\#}$ & $\checkmark$ & $\checkmark$ & $\checkmark$ & $\checkmark$ & $\checkmark$ & $\checkmark$ & $\checkmark$ & $\checkmark$ & $\checkmark$ & $\sigma^{\#}$ & $\checkmark$ \\
\hline & Raman & $x$ & $\mathcal{J}^{\#}$ & $\mathcal{S}^{\#}$ & $\mathcal{J}^{\#}$ & $\checkmark$ & $\checkmark$ & $\checkmark$ & $\checkmark$ & $\checkmark$ & $\checkmark$ & $\checkmark$ & $\checkmark$ & $\checkmark$ & $\mathcal{J}^{\#}$ & $\checkmark$ \\
\hline \multirow{4}{*}{$510 \mathrm{M} \mathrm{NaOH}\left(60^{\circ} \mathrm{C}, 24 \mathrm{~h}\right)$} & Weighing & $x$ & NA & $\checkmark$ & $\checkmark$ & $\checkmark$ & $\checkmark$ & $x$ & $x$ & $\checkmark$ & $\checkmark$ & $\checkmark$ & $\checkmark$ & $\checkmark$ & $\checkmark$ & $\checkmark$ \\
\hline & Visual & $\mathrm{Sh}, \mathrm{Si}$ & $\checkmark$ & $\checkmark$ & $\checkmark$ & $\checkmark$ & $\checkmark$ & Sh, Si & $\mathrm{Sh}, \mathrm{Si}$ & $\checkmark$ & $\checkmark$ & $\checkmark$ & $\checkmark$ & $\checkmark$ & $\checkmark$ & $\checkmark$ \\
\hline & Pyr-GC/MS & $x$ & $\mathcal{J}^{\#}$ & $\Omega^{\#}$ & $\checkmark^{\#}$ & $\checkmark$ & $\checkmark$ & NA & $\checkmark$ & $\checkmark$ & $\checkmark$ & $\checkmark$ & $\checkmark$ & $\checkmark$ & $\sigma^{\#}$ & $\checkmark$ \\
\hline & Raman & $\checkmark$ & $\checkmark^{\#}$ & $\checkmark^{\#}$ & $\checkmark^{\#}$ & $\checkmark$ & $\checkmark$ & NA & $\checkmark$ & $\checkmark$ & $\checkmark$ & $\checkmark$ & $\checkmark$ & $\checkmark$ & $\boldsymbol{J}^{\#}$ & $\checkmark$ \\
\hline \multirow{4}{*}{$60.27 \mathrm{M} \mathrm{K}_{2} \mathrm{~S}_{2} \mathrm{O}_{8} / 0.24 \mathrm{M} \mathrm{NaOH}\left(65^{\circ} \mathrm{C}, 24 h\right)$} & Weighing & $x$ & NA & $\checkmark$ & $\checkmark$ & $\checkmark$ & $\boldsymbol{J}^{*}$ & $\checkmark$ & $\checkmark$ & $J^{*}$ & $\checkmark$ & $\checkmark$ & $\Omega^{*}$ & $\checkmark$ & $\checkmark$ & $\checkmark$ \\
\hline & Visual & Sh, Si & $\checkmark$ & $\checkmark$ & $\checkmark$ & $\checkmark$ & $\checkmark$ & $\checkmark$ & $\checkmark$ & $\checkmark$ & $\checkmark$ & $\checkmark$ & $\checkmark$ & $\checkmark$ & $\checkmark$ & $\checkmark$ \\
\hline & Pyr-GC/MS & $\checkmark$ & $\sigma^{\#}$ & $\sigma^{\#}$ & $\sigma^{\#}$ & $\checkmark$ & $\checkmark$ & $\checkmark$ & $\checkmark$ & $\checkmark$ & $\checkmark$ & $\checkmark$ & $\checkmark$ & $x$ & $\mathcal{J}^{\#}$ & $\checkmark$ \\
\hline & Raman & $\checkmark$ & $J^{\#}$ & $\mathcal{J}^{\#}$ & $\boldsymbol{J}^{\#}$ & $\checkmark$ & $\checkmark$ & $\checkmark$ & $\checkmark$ & $\checkmark$ & $\checkmark$ & $\checkmark$ & $\checkmark$ & $\checkmark$ & $\boldsymbol{J}^{\#}$ & $\checkmark$ \\
\hline
\end{tabular}

(CA: cellulose acetate; ePS: expanded polystyrene; HDPE: high density polyethylene; LDPE: low density polyethylene; PA: polyamide; PA-12: polylauryllactam; PA-6: polycaprolactam; PC: polycarbonate; PE: polyethylene; PET: polyethylene terephthalate; PMMA: poly(methyl-methacrylate); PP: polypropylene; PS: polystyrene; PTFE: polytetrafluoroethylene; PUR: polyurethane; PSXL: crosslinked polystyrene; uPVC: unplasticized polyvinyl chloride).

$\checkmark$ : weighing, visual (absence of noticeable change) and identification analysis passed.

$\boldsymbol{x}$ : degraded polymers or identification problem.

Sh: change in the shape.

Si: change in the size.

“*”: no change on weighing analysis for 2 out of 3 analysis.

"\#": only native molecule identified (not the type of polymerization).

NA: not analysed because of technical issues. 
Table 2

Quality of the digestion, filtration and filter observations after digestion of mussels, crabs and fish tissues following protocols $1 \mathrm{~b}\left(\mathrm{KOH} 10 \%, 24 \mathrm{~h}, 60{ }^{\circ} \mathrm{C}\right)$ and $6\left(\mathrm{~K}_{2} \mathrm{~S}_{2} \mathrm{O}_{8} / \mathrm{NaOH}\right.$ $\left.65^{\circ} \mathrm{C}, 24 \mathrm{~h}\right)$. (NA: not analysed).

\begin{tabular}{|c|c|c|c|}
\hline Tissues & Steps & Protocol 1b & Protocol 6 \\
\hline \multirow{4}{*}{ Mussels } & Digestion & $\begin{array}{l}\text { Good } \\
\text { No particle visible to the naked eye in the digestate. }\end{array}$ & $\begin{array}{l}\text { Bad } \\
\text { Presence of small organic/inorganic fragments. } \\
\text { Hepatopancreas not diges-ted }\end{array}$ \\
\hline & & Use of a single GF/A $1.6 \mu \mathrm{m}$ filter. & $\begin{array}{l}\text { One to two filters used depending on the individuals. } \\
\text { Rapid clogging. }\end{array}$ \\
\hline & Filter & Good & Bad \\
\hline & & Negligible amount of debris. Filter lightly loaded. & $\begin{array}{l}\text { High quantity of debris leading to inability to accurately } \\
\text { detect micro-plastics. }\end{array}$ \\
\hline \multirow{3}{*}{ Crabs } & Digestion & $\begin{array}{l}\text { Good } \\
\text { No particle visible to the naked eye in the digestate. Pieces of cartilage } \\
\text { rinsed with distilled water. }\end{array}$ & NA \\
\hline & Filtration & $\begin{array}{l}\text { Good } \\
\text { Use of a single GF/A } 1.6 \mu \mathrm{m} \text { filter. }\end{array}$ & NA \\
\hline & Filter & $\begin{array}{l}\text { Good } \\
\text { Negligible amount of debris. Filter lightly loaded. }\end{array}$ & NA \\
\hline \multirow{3}{*}{$\begin{array}{l}\text { Fish } \\
\text { (fillet) }\end{array}$} & Digestion & $\begin{array}{l}\text { Good } \\
\text { No particle visible to the naked eye in the digestate. Pieces of fish bones } \\
\text { rinsed with distilled water. }\end{array}$ & NA \\
\hline & Filtration & $\begin{array}{l}\text { Good } \\
\text { Use of a single GF/A } 1.6 \mu \mathrm{m} \text { filter. }\end{array}$ & NA \\
\hline & Filter & $\begin{array}{l}\text { Good } \\
\text { Negligible amount of debris. Filter lightly loaded }\end{array}$ & NA \\
\hline \multirow{4}{*}{$\begin{array}{l}\text { Fish (whole } \\
\text { alimentary tract) }\end{array}$} & Digestion & $\begin{array}{l}\text { Poor } \\
\text { Particle visible to the naked eye in the digestate. Dense digestate (mærl, } \\
\text { sand, etc.). }\end{array}$ & NA \\
\hline & Filtration & $\begin{array}{l}\text { Bad } \\
\text { Impossible to filter due to clogging. }\end{array}$ & NA \\
\hline & $\begin{array}{l}\text { Filtration } \\
\text { (after } \\
\text { separation step) }\end{array}$ & $\begin{array}{l}\text { Good } \\
\text { The use to sodium tungstate facilitated the filtration step. Use of a single } \\
\text { GF/A } 1.6 \mu \mathrm{m} \text { filter. }\end{array}$ & NA \\
\hline & Filter & $\begin{array}{l}\text { Good } \\
\text { Absence or negligible amount of debris. Filter lightly loaded. }\end{array}$ & NA \\
\hline
\end{tabular}




\section{Microplastics in seafood: benchmark protocol for their extraction and characterization}

Alexandre DEHAUTa, Anne-Laure CASSONE ${ }^{b}$, Laura FRERE, Ludovic HERMABESSIEREa ${ }^{a}$ Charlotte HIMBER$^{a}$, Emmanuel RINNERTc, Gilles RIVIERE ${ }^{d}$, Christophe LAMBERT ${ }^{b}$, Philippe SOUDANT ${ }^{b}$, Arnaud HUVETe, Guillaume DUFLOSa \& Ika PAUL-PONT'b,

a ANSES - Laboratoire de Sécurité des Aliments - Boulevard du Bassin Napoléon, 62200 Boulogne-sur-Mer, France.

b Laboratoire des Sciences de l'Environnement Marin (LEMAR) - UMR6539 / UBO / CNRS / IRD / IFREMER Institut Universitaire Européen de la Mer, Technopôle Brest-Iroise - Rue Dumont d'Urville, 29280 Plouzané, France.

c IFREMER - Laboratoire Détection, Capteurs et Mesures (LDCM) - Centre Bretagne, ZI de la Pointe du Diable CS 10070, 29280 Plouzané, France.

${ }^{d}$ ANSES - Direction d'Evaluation des Risques - 14, rue Pierre et Marie Curie, 94701 Maisons-Alfort Cedex, France.

e IFREMER - Laboratoire des Sciences de l'Environnement Marin (LEMAR) - UMR 6539 / UBO / CNRS / IRD / IFREMER, 29280 Plouzané, France.

${ }^{*}$ Corresponding author: E-mail: ika.paulpont[at]univ-brest.fr Phone: +33 298498867 Fax: +33 298498645

\section{Supplementary files}

Supplemental Table 1: Plastics and their common brand names

Supplemental Table 2: Plastic weights before and after application of the protocols of the preliminary study .....

Supplemental Figure 1: Plastic weights before and after application of protocol $1 \mathrm{~b}$

Supplemental Figure 2: Plastic weights before and after application of protocol 5 5

Supplemental Figure 3: Plastic weights before and after application of protocol 6 6

Supplemental Figure 4: Test of Protocols 5 and 6 on PA-6 fibres 7

Supplemental Figure 5: Filters corresponding to digestion of mussel tissues with protocols $1 \mathrm{~b}$ and 6 .. 8

Supplemental Figure 6: Comparison of $\% D e$ for mussels treated by protocol $1 \mathrm{~b}$ with different conditions (200 mL at $300 \mathrm{rpm}$ vs. $100 \mathrm{~mL}$ at $200 \mathrm{rpm}$ ).

Supplemental Figure 7: Filters corresponding to digestion of crab tissues with protocol $1 \mathrm{~b} \ldots \ldots \ldots \ldots \ldots . . . .10$

Supplemental Figure 8: Filters corresponding to digestion of fish tissues with protocol $1 \mathrm{~b}$. 11 


\section{Supplemental Table 1: Plastics and their common brand names}

\begin{tabular}{lcl}
\hline Polymers & Abbreviations & \multicolumn{1}{c}{ Common brand names } \\
\hline Cellulose acetate & CA & Clarifoil, Dexel, Tenite Acetate \\
High density polyethylene & HDPE & Hostalen HD, Lacqtene HD, Lupolen, Rigidex \\
Low density polyethylene & LDPE & Alkathene, Carlona, Lacqtene, Lupolen, Stamylan LD \\
Polylauryllactam & PA-12 & Rilsan A, Vestamid \\
Polycaprolactam & PA-6 & Akulon K and F, Capron, Maranyl B, Nylacast, Orgamid, \\
& & Ultramid B \\
Polycarbonate & PC & Lexan, Makrofol, Makrolon \\
Polyethylene terephthalate & PET & Arnite, Dacron, Hostaphan, Impet, Melinar, Melinex, \\
& & Mylar, Rynite, Terylene, Trevira \\
Poly(methyl-methacrylate) & PMMA & Diakon, Lucite, Oroglas, Perspex, Plexiglas \\
Polypropylene & PP & Appryl, Hostalen PP, Lacqtene, Novolen, Propathene \\
Polystyrene & PS & - \\
Crosslinked polystyrene & PSXL & Q.200.5, Rexolite \\
Polytetrafluoroethylene & PTFE & Fluon, Hostaflon TF \\
Polyurethane & PUR & - \\
unplasticized Polyvinyl chloride & uPVC & Corvic, Evipol, Geon, Hostalit, Lacovyl, Lucorex \\
\hline
\end{tabular}




\section{Supplemental Table 2: Plastic weights before and after application of the protocols of the preliminary study}

\begin{tabular}{|c|c|c|c|c|c|c|c|c|c|c|}
\hline & \multicolumn{2}{|c|}{ HDPE } & \multicolumn{2}{|c|}{ PP } & \multicolumn{2}{|c|}{ LDPE } & \multicolumn{2}{|c|}{ PS } & \multicolumn{2}{|c|}{ PA-12 } \\
\hline & Before & After & Before & After & Before & After & Before & After & Before & After \\
\hline S1 & $2,3 \pm 0,2$ & $2,3 \pm 0,0$ & $25,6 \pm 0,1$ & $5,6 \pm 0,1$ & $3,6 \pm 0,1$ & $3,5 \pm 0,0$ & $15,5 \pm 0,1$ & $15,5 \pm 0,0$ & $15,5 \pm 0,0$ & $15,5 \pm 0,0$ \\
\hline P1 S2 & $2,6 \pm 0,1$ & $2,7 \pm 0,1$ & $22,1 \pm 0,0$ & $22,1 \pm 0,1$ & $3,3 \pm 0,1$ & $3,3 \pm 0,1$ & $20,0 \pm 0,0$ & $20,0 \pm 0,0$ & $15,8 \pm 0,1$ & $15,8 \pm 0,1$ \\
\hline S3 & $2,5 \pm 0,1$ & $2,6 \pm 0,1$ & $21,9 \pm 0,1$ & $21,9 \pm 0,1$ & $3,5 \pm 0,1$ & $3,5 \pm 0,1$ & $14,3 \pm 0,1$ & $14,3 \pm 0,1$ & $16,1 \pm 0,1$ & $16,2 \pm 0,1$ \\
\hline S1 & $2,1 \pm 0,1$ & $2,1 \pm 0,1$ & $19,1 \pm 0,0$ & $19,2 \pm 0,1$ & $2,5 \pm 0,0$ & $2,6 \pm 0,1$ & $16,3 \pm 0,0$ & $16,3 \pm 0,1$ & $16,7 \pm 0,1$ & $16,7 \pm 0,1$ \\
\hline P2 S2 & $2,3 \pm 0,1$ & $2,3 \pm 0,1$ & $19,4 \pm 0,1$ & $19,4 \pm 0,1$ & $2,8 \pm 0,1$ & $2,8 \pm 0,1$ & $3,0 \pm 0,0$ & $3,1 \pm 0,1$ & $16,2 \pm 0,1$ & $16,2 \pm 0,1$ \\
\hline S3 & $2,5 \pm 0,1$ & $2,5 \pm 0,0$ & $23,8 \pm 0,1$ & $23,9 \pm 0,0$ & $1,6 \pm 0,1$ & $1,8 \pm 0,1$ & $16,2 \pm 0,0$ & $16,2 \pm 0,1$ & $7,4 \pm 0,1$ & $7,3 \pm 0,1$ \\
\hline S1 & $2,9 \pm 0,1$ & $2,8 \pm 0,1$ & $21,0 \pm 0,0$ & $21,0 \pm 0,1$ & $4,9 \pm 0,0$ & $4,9 \pm 0,1$ & $14,5 \pm 0,0$ & $14,5 \pm 0,1$ & $9,8 \pm 0,1$ & $9,5 \pm 0,1 *$ \\
\hline P3 S2 & $2,6 \pm 0,0$ & $2,6 \pm 0,0$ & $19,8 \pm 0,1$ & $19,7 \pm 0,1$ & $3,6 \pm 0,1$ & $3,5 \pm 0,1$ & $16,6 \pm 0,1$ & $16,7 \pm 0,1$ & $13,1 \pm 0,1$ & $12,2 \pm 0,1 *$ \\
\hline S3 & $3,6 \pm 0,1$ & $3,5 \pm 0,1$ & $20,9 \pm 0,1$ & $20,9 \pm 0,1$ & $2,3 \pm 0,1$ & $2,3 \pm 0,1$ & $17,4 \pm 0,1$ & $17,5 \pm 0,1$ & $15,9 \pm 0$ & $15,5 \pm 0,1 *$ \\
\hline S1 & $2,0 \pm 0,1$ & $2,0 \pm 0,1$ & $24,6 \pm 0,1$ & $24,6 \pm 0,1$ & $1,1 \pm 0,0$ & $1,1 \pm 0,0$ & $18,3 \pm 0,1$ & $18,3 \pm 0,1$ & $19 \pm 0,1$ & $11,8 \pm 0,1 *$ \\
\hline P4 S2 & $1,6 \pm 0,1$ & $1,6 \pm 0,1$ & $22,3 \pm 0,1$ & $22,3 \pm 0,1$ & $4,3 \pm 0,0$ & $4,3 \pm 0,0$ & $16,1 \pm 0,1$ & $16,2 \pm 0$ & $15,2 \pm 0,1$ & $6 \pm 0,1 *$ \\
\hline S3 & $2,3 \pm 0,1$ & $2,4 \pm 0,1$ & $22,7 \pm 0,1$ & $22,8 \pm 0,1$ & $2,1 \pm 0,1$ & $2,1 \pm 0,1$ & $16,9 \pm 0,1$ & $17 \pm 0$ & $9,7 \pm 0$ & $4,3 \pm 0,1 *$ \\
\hline S1 & $2,6 \pm 0,0$ & $2,6 \pm 0,1$ & $7,7 \pm 0,1$ & $7,7 \pm 0,1$ & $2,3 \pm 0$ & $2,3 \pm 0,1$ & $14,1 \pm 0,2$ & $14,1 \pm 0,1$ & $11,3 \pm 0,1$ & $11,2 \pm 0,1$ \\
\hline P5 S2 & $3,6 \pm 0,1$ & $3,6 \pm 0,1$ & $4,7 \pm 0,1$ & $4,7 \pm 0,1$ & $2,9 \pm 0,1$ & $2,8 \pm 0,1$ & $18,5 \pm 0,1$ & $18,5 \pm 0,1$ & $15,7 \pm 0,1$ & $15,7 \pm 0,1$ \\
\hline S3 & $1,5 \pm 0,0$ & $1,5 \pm 0,0$ & $5,3 \pm 0,1$ & $5,3 \pm 0,1$ & $1,0 \pm 0,0$ & $0,9 \pm 0,1$ & $11,7 \pm 0,1$ & $11,6 \pm 0,1$ & $7,4 \pm 0,1$ & $7,3 \pm 0,1$ \\
\hline S1 & $22,0 \pm 0,1$ & $22,1 \pm 0,1$ & $25,0 \pm 0,0$ & $25,1 \pm 0,1$ & $25,0 \pm 0,1$ & $24,9 \pm 0,1$ & $16,3 \pm 0,0$ & $16,2 \pm 0,1$ & $15,9 \pm 0$ & $15,7 \pm 0,1$ \\
\hline P6 S2 & $19,4 \pm 0,1$ & $19,3 \pm 0,1$ & $18,3 \pm 0,1$ & $18,2 \pm 0,1$ & $22,1 \pm 0,0$ & $22,0 \pm 0,1$ & $17,0 \pm 0,1$ & $17 \pm 0,1$ & $19,5 \pm 0,1$ & $19,5 \pm 0$ \\
\hline S3 & $16,5 \pm 0,1$ & $16,5 \pm 0,0$ & $21,9 \pm 0,1$ & $21,9 \pm 0,1$ & $24,5 \pm 0,1$ & $24,5 \pm 0,0$ & $15,3 \pm 0,1$ & $15,1 \pm 0,1$ & $14,8 \pm 0$ & $14,8 \pm 0,1$ \\
\hline
\end{tabular}

(HDPE: high density polyethylene; LDPE: low density polyethylene; PA-12: polylauryllactam ; PP: polypropylene; PS: polystyrene)

P1: Protocol 1 (10\% KOH, 3 weeks, Room temperature); P2: Protocol 2 (0.5\%Pepsin, $\left.2 \mathrm{~h}, 37{ }^{\circ} \mathrm{C}\right)$; P3: Protocol $3\left(65 \% \mathrm{HNO}_{3}\right.$ at room temperature overnight, then $60{ }^{\circ} \mathrm{C}$ for $2 \mathrm{~h}$ ); P4: Protocol $4\left(4: 1(\mathrm{v} / \mathrm{v})\right.$ mix of $65 \% \mathrm{HNO}_{3}$ and $65 \% \mathrm{HClO}_{4}$ at room temperature overnight, then boiled for $\left.10 \mathrm{~min}\right)$; P5: Protocol $5\left(10 \mathrm{M} \mathrm{NaOH}, 60^{\circ} \mathrm{C}, 24 \mathrm{~h}\right)$; P6: Protocol $6\left(\mathrm{~K}_{2} \mathrm{~S}_{2} \mathrm{O}_{8} / \mathrm{NaOH}, 65^{\circ} \mathrm{C}, 24 \mathrm{~h}\right)$

$\mathrm{S} 1, \mathrm{~S} 2, \mathrm{~S} 3$ correspond to the three sample of the triplicate analysis

Weighing (mg) are expressed as mean \pm s.d

'*' Samples that melted during the application of digestion protocol 

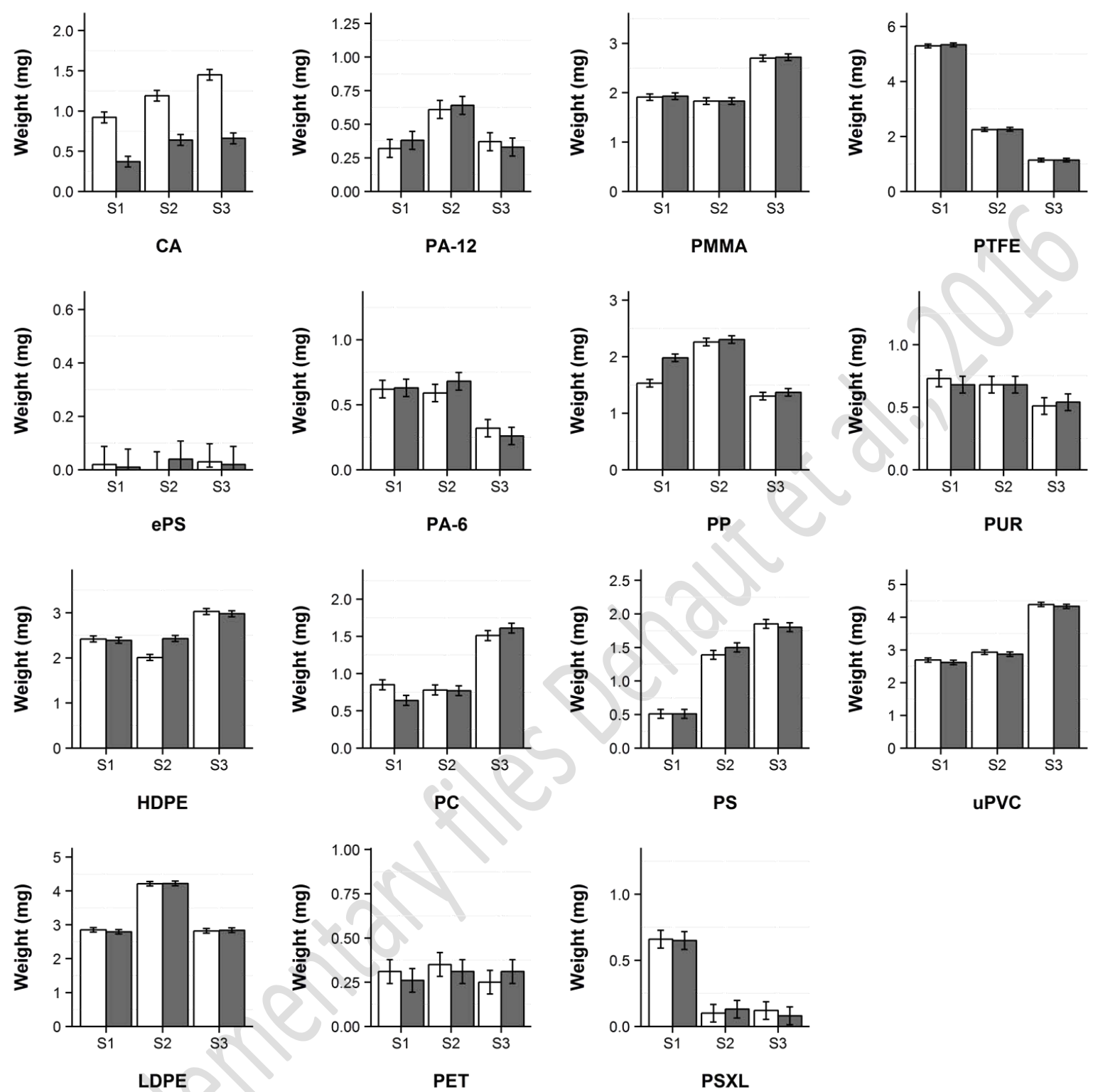

Bar chart representing change in weight (mg) for cellulose acetate (CA); expanded polystyrene (ePS); high density polyethylene (HDPE); low density polyethylene (LDPE); polylauryllactam (PA-12); polycaprolactam (PA-6); polycarbonate (PC); polyethylene terephthalate (PET); poly(methylmethacrylate) (PMMA); polypropylene (PP); polystyrene (PS); polytetrafluoroethylene (PTFE); polyurethane (PUR); cross-linked polystyrene (PSXL); unplasticized polyvinyl chloride (uPVC); before and after application of protocol $1 \mathrm{~b}, 10 \% \mathrm{KOH}, 24 \mathrm{~h}, 60^{\circ} \mathrm{C}$. White and dark grey bars represent the mean of 5 repeated weight measures of three plastic samples (S1, S2 \& S3) respectively before and after application of protocols. Error bars on charts represent the expanded weighing uncertainty of the results Ueb (see 2.4). 


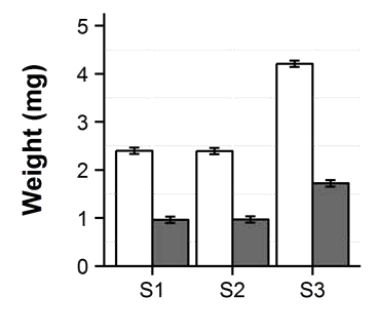

CA
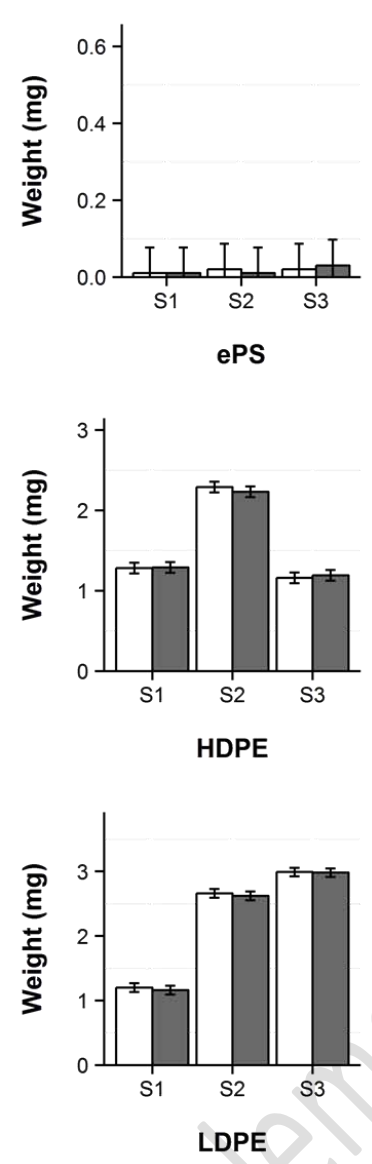

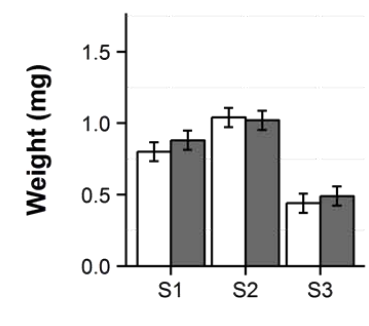

PA-12
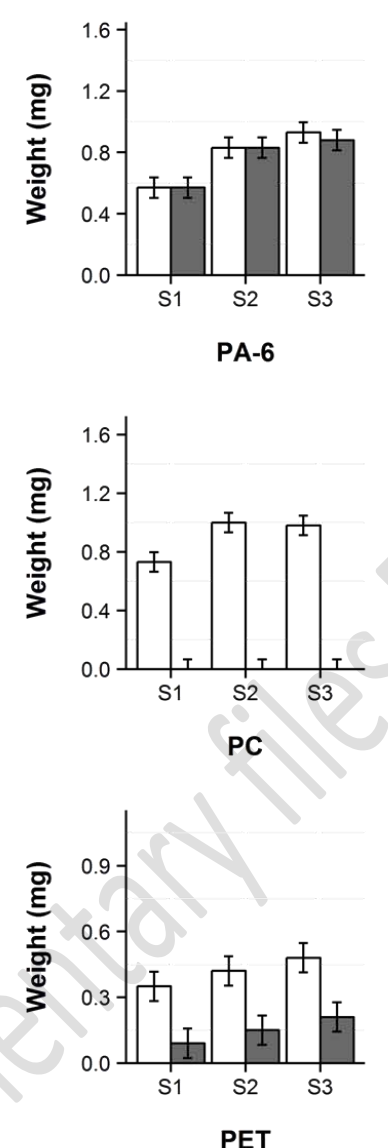
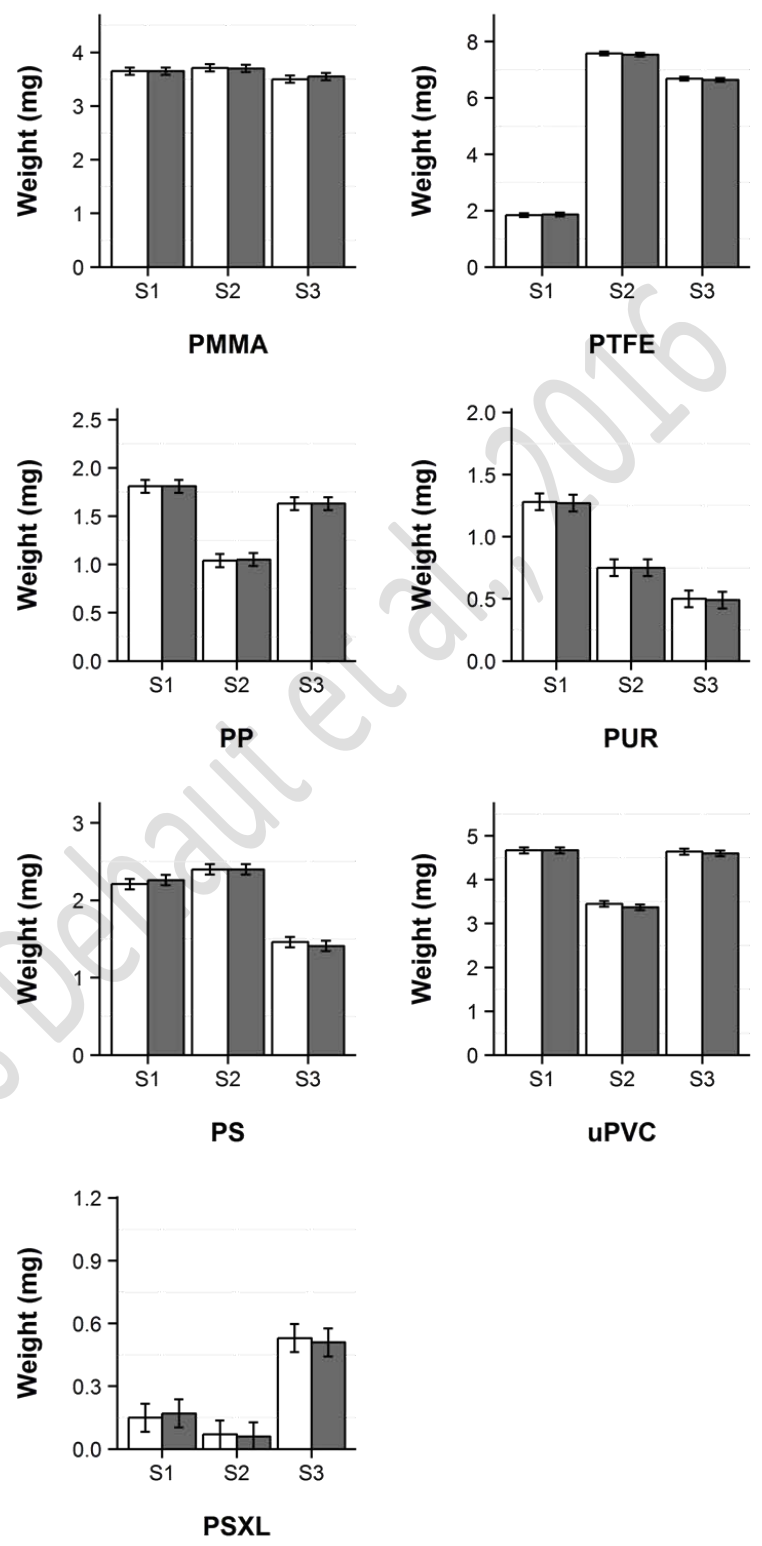

Bar chart representing change in weight (mg) for cellulose acetate (CA); expanded polystyrene (ePS); high density polyethylene (HDPE); low density polyethylene (LDPE); polylauryllactam (PA-12); polycaprolactam (PA-6); polycarbonate (PC); polyethylene terephthalate (PET); poly(methylmethacrylate) (PMMA); polypropylene (PP); polystyrene (PS); polytetrafluoroethylene (PTFE); polyurethane (PUR); cross-linked polystyrene (PSXL); unplasticized polyvinyl chloride (uPVC); before and after application of protocol $5,10 \mathrm{M} \mathrm{NaOH} 60^{\circ} \mathrm{C}, 24 \mathrm{~h}$. White and dark grey bars represent the mean of 5 repeated weight measures of three plastic samples (S1, S2 \& S3) respectively before and after application of protocols. Error bars on charts represent the expanded weighing uncertainty of the results Ueb (see 2.4). 

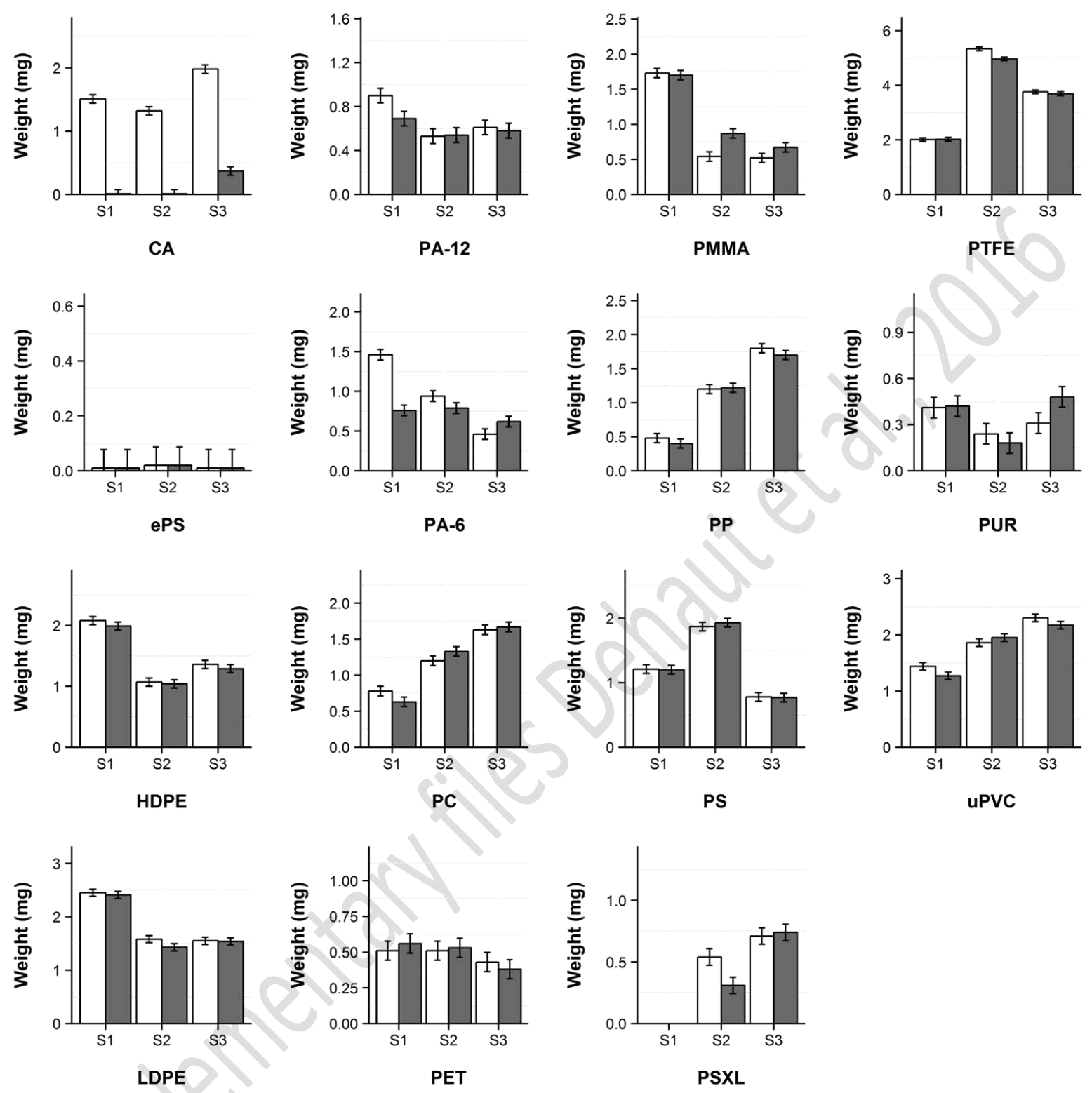

Bar chart representing change in weight (mg) for cellulose acetate (CA); expanded polystyrene (ePS); high density polyethylene (HDPE); low density polyethylene (LDPE); polylauryllactam (PA-12); polycaprolactam (PA-6); polycarbonate (PC); polyethylene terephthalate (PET); poly(methylmethacrylate) (PMMA); polypropylene (PP); polystyrene (PS); polytetrafluoroethylene (PTFE); polyurethane (PUR); cross-linked polystyrene (PSXL); unplasticized polyvinyl chloride (uPVC); before and after application of protocol $6, \mathrm{~K}_{2} \mathrm{~S}_{2} \mathrm{O}_{8} / \mathrm{NaOH} 65^{\circ} \mathrm{C}, 24 \mathrm{~h}$. One sample of PSXL was lost during the second weighing. White and dark grey bars represent the mean of 5 repeated weight measures of three plastic samples (S1, S2 \& S3) respectively before and after application of protocols. Error bars on charts represent the expanded weighing uncertainty of the results $\mathrm{Ueb}$ (see 2.4). 


\section{Before}
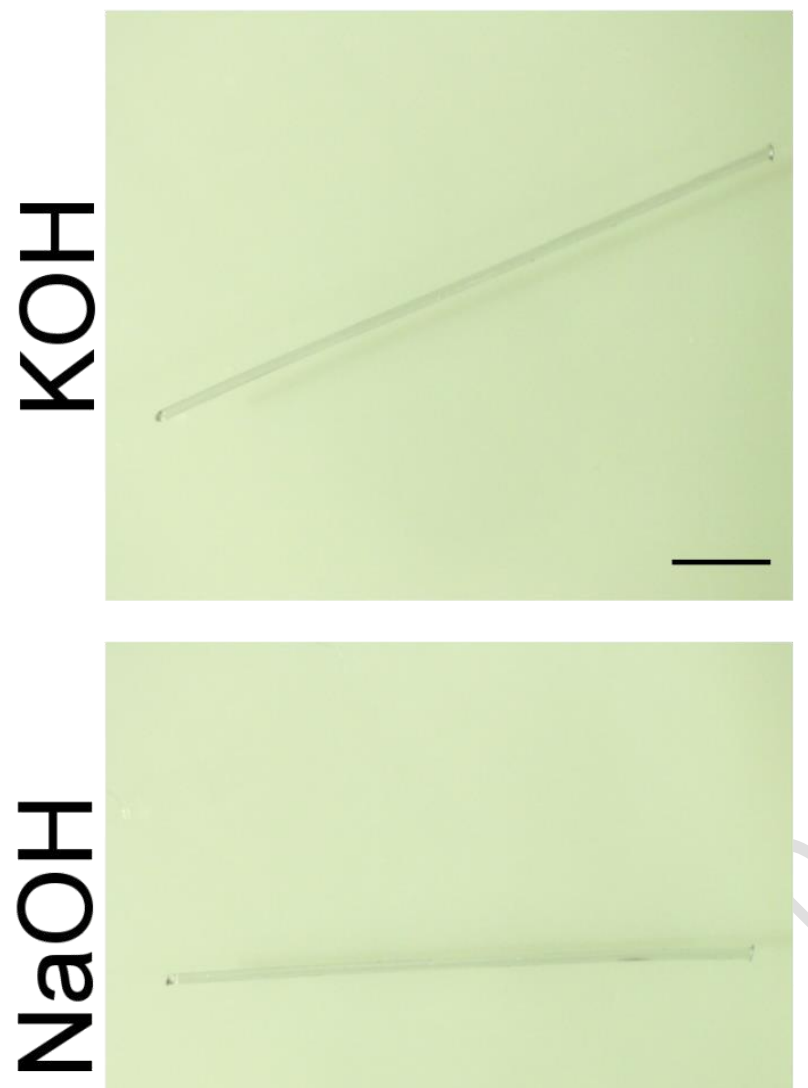

After
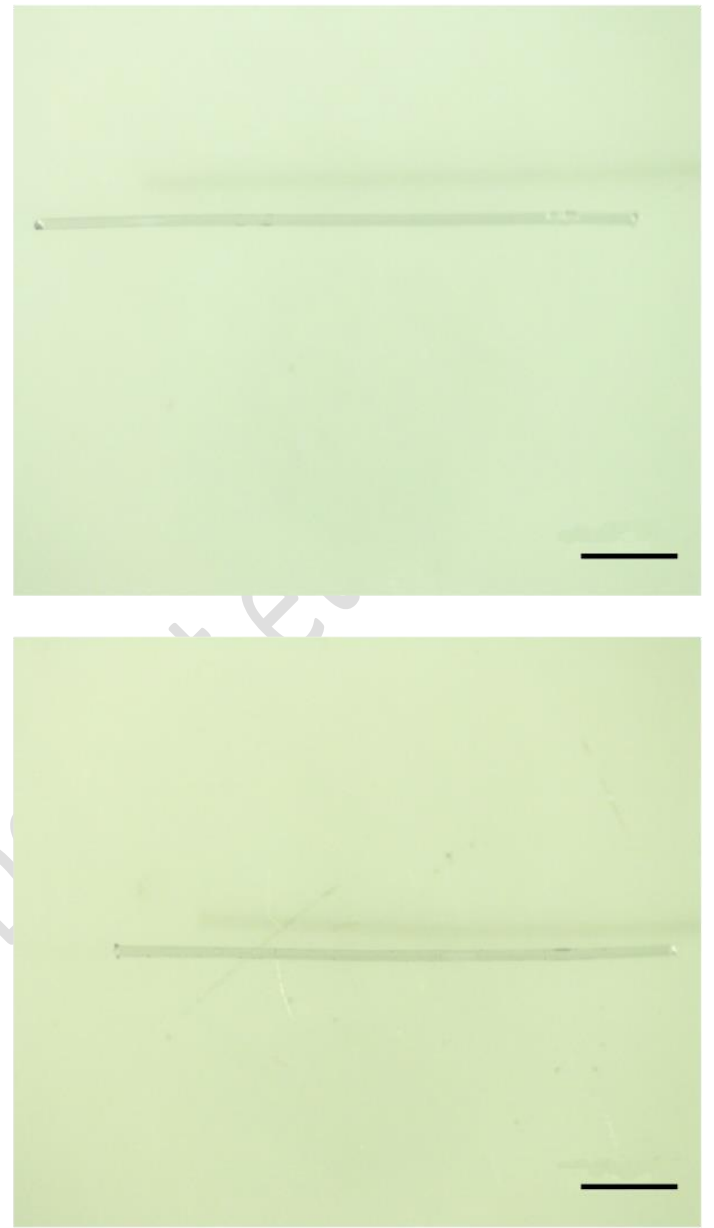

Visual inspection of nylon fibres (PA-6) before and after application of protocol $5\left(10 \mathrm{M} \mathrm{NaOH} 60^{\circ} \mathrm{C}, 24 \mathrm{~h}\right)$ and $6\left(\mathrm{~K}_{2} \mathrm{~S}_{2} \mathrm{O}_{8} / \mathrm{NaOH} 65^{\circ} \mathrm{C}\right.$, 24h). No significant change was observed and identification by Pyr-GC/MS led to good identification with respective similarities of 96 and $99 \%$. 
Supplemental Figure 5: Filters corresponding to digestion of mussel tissues with protocols $1 \mathrm{~b}$ and 6

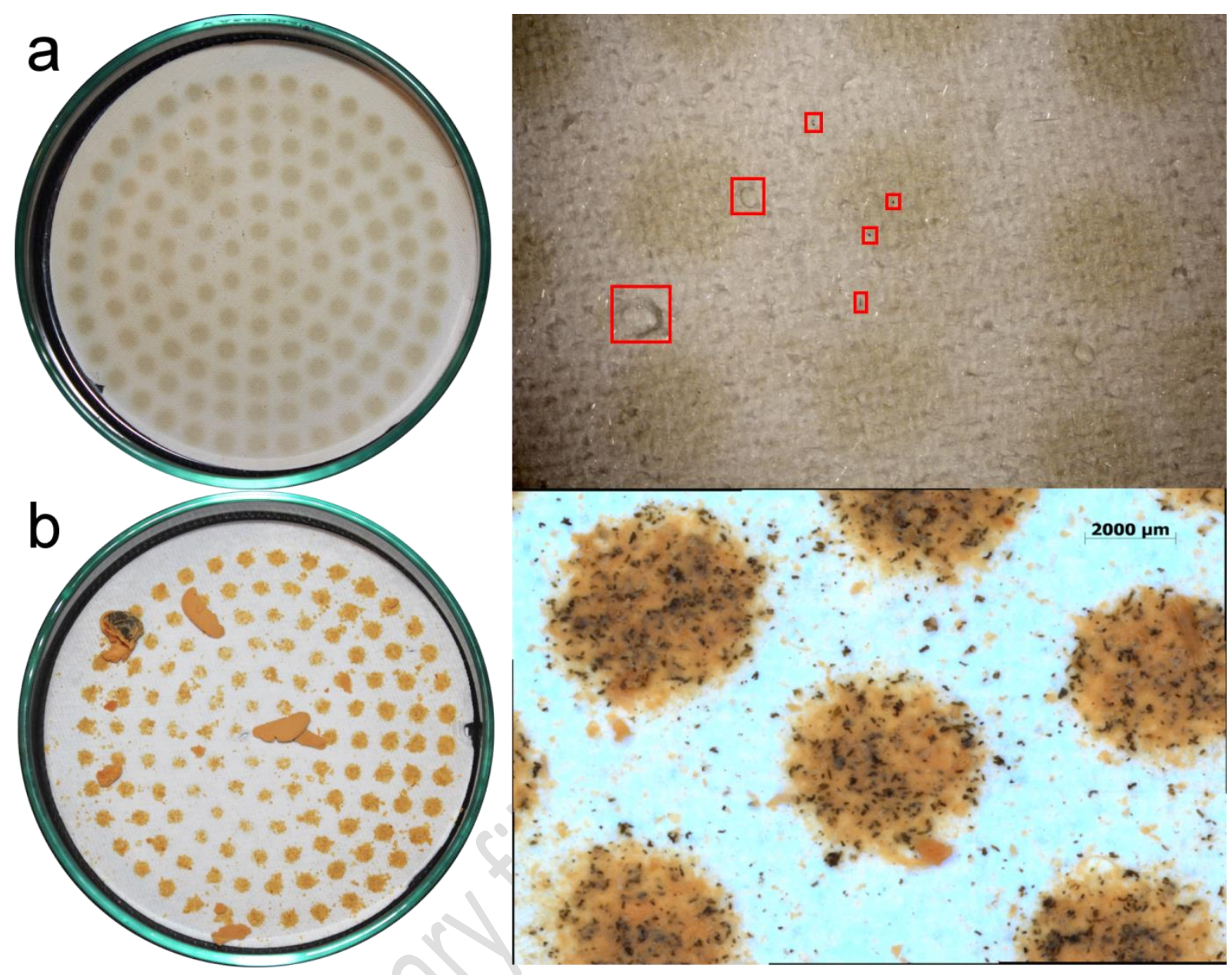

Filters corresponding to digestion of mussel tissues with protocols $1 \mathrm{~b}\left(10 \% \mathrm{KOH}, 24 \mathrm{~h}, 60{ }^{\circ} \mathrm{C}\right)(\mathrm{a})$ and 6 $\left(\mathrm{K}_{2} \mathrm{~S}_{2} \mathrm{O}_{8} / \mathrm{NaOH} 65^{\circ} \mathrm{C}, 24 \mathrm{~h}\right)(\mathrm{b})$. Areas highlighted by red squares correspond to fragments suspected to be microplastics. 
Supplemental Figure 6: Comparison of $\% D e$ for mussels treated by protocol $1 \mathrm{~b}$ with different conditions ( $200 \mathrm{~mL}$ at $300 \mathrm{rpm}$ vs. $100 \mathrm{~mL}$ at $200 \mathrm{rpm})$.

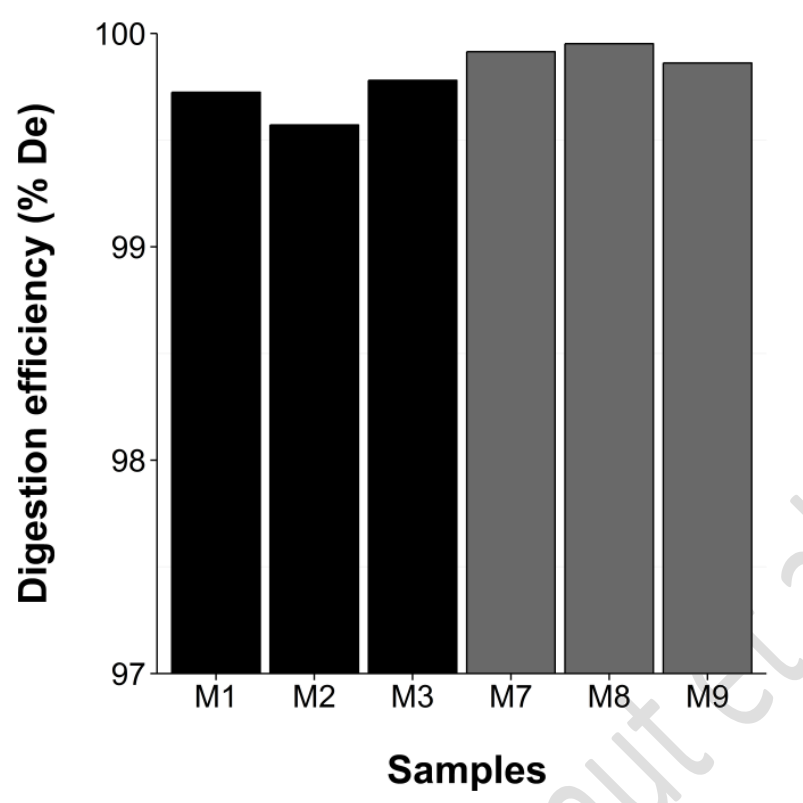

Bar chart representing individual digestion efficiencies (\% De ) on three mussels, M1 to M3 for protocol $1 \mathrm{~b}$ $\left(200 \mathrm{~mL}\right.$ of $\left.10 \% \mathrm{KOH}, 300 \mathrm{rpm}, 24 \mathrm{~h}, 6^{\circ} \mathrm{C}\right)$ in black, and $\mathrm{M} 7$ to $\mathrm{M9}$ for protocol $1 \mathrm{~b}(100 \mathrm{~mL} \mathrm{of} 10 \%$ $\left.\mathrm{KOH}, 200 \mathrm{rpm}, 24 \mathrm{~h}, 60^{\circ} \mathrm{C}\right)$ in grey. The very low standard deviations $(<0.01 \%)$ do not appear on bar diagrams as they could not be distinctively traced. 
Supplemental Figure 7: Filters corresponding to digestion of crab tissues with protocol 1b.

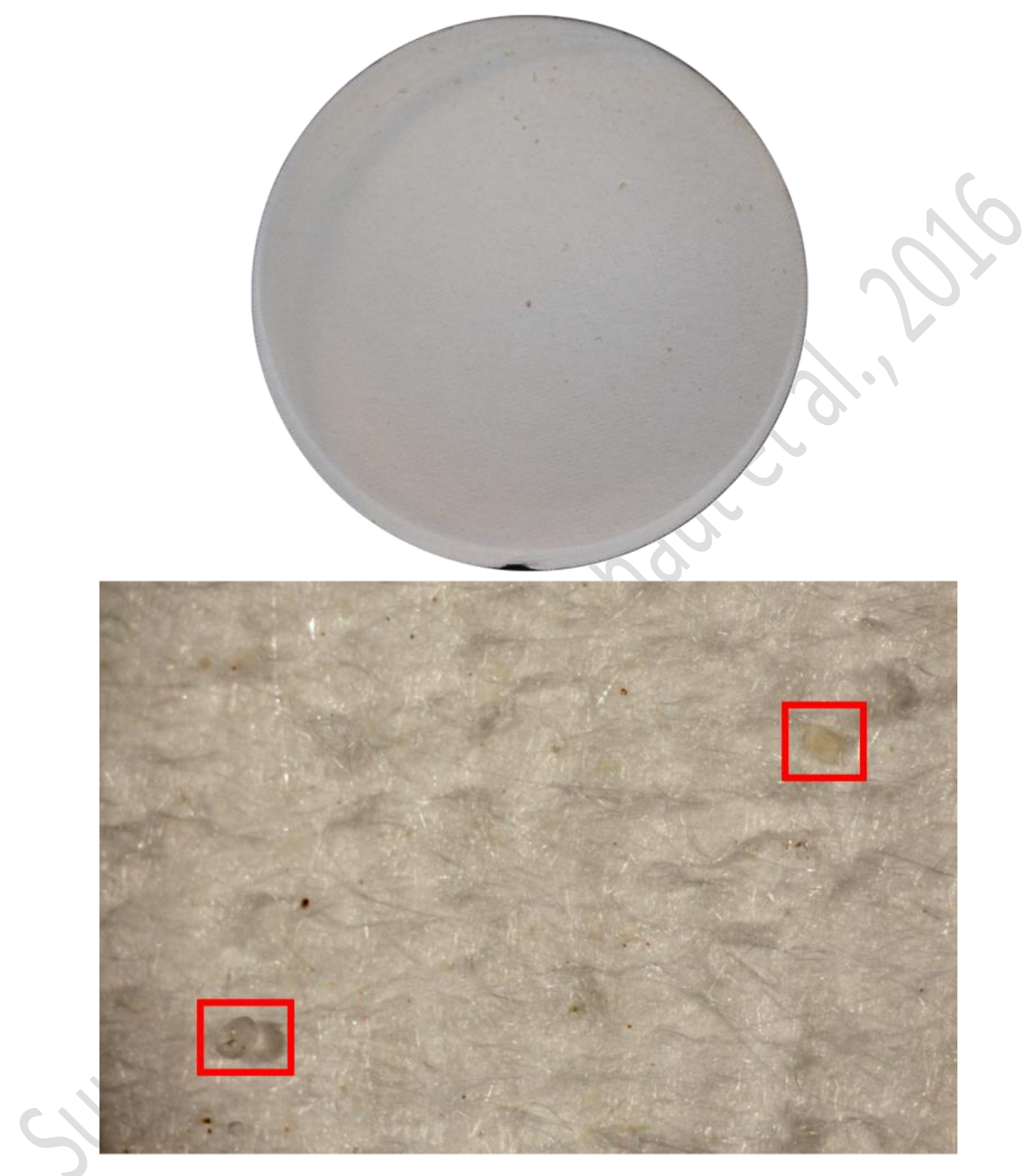

Filter corresponding to digestion of crab tissues with protocol $1 \mathrm{~b}\left(10 \% \mathrm{KOH}, 24 \mathrm{~h}, 60{ }^{\circ} \mathrm{C}\right)$. Areas highlighted by red squares correspond to suspected microplastic fragments. 
Supplemental Figure 8: Filters corresponding to digestion of fish tissues with protocol $1 b$.

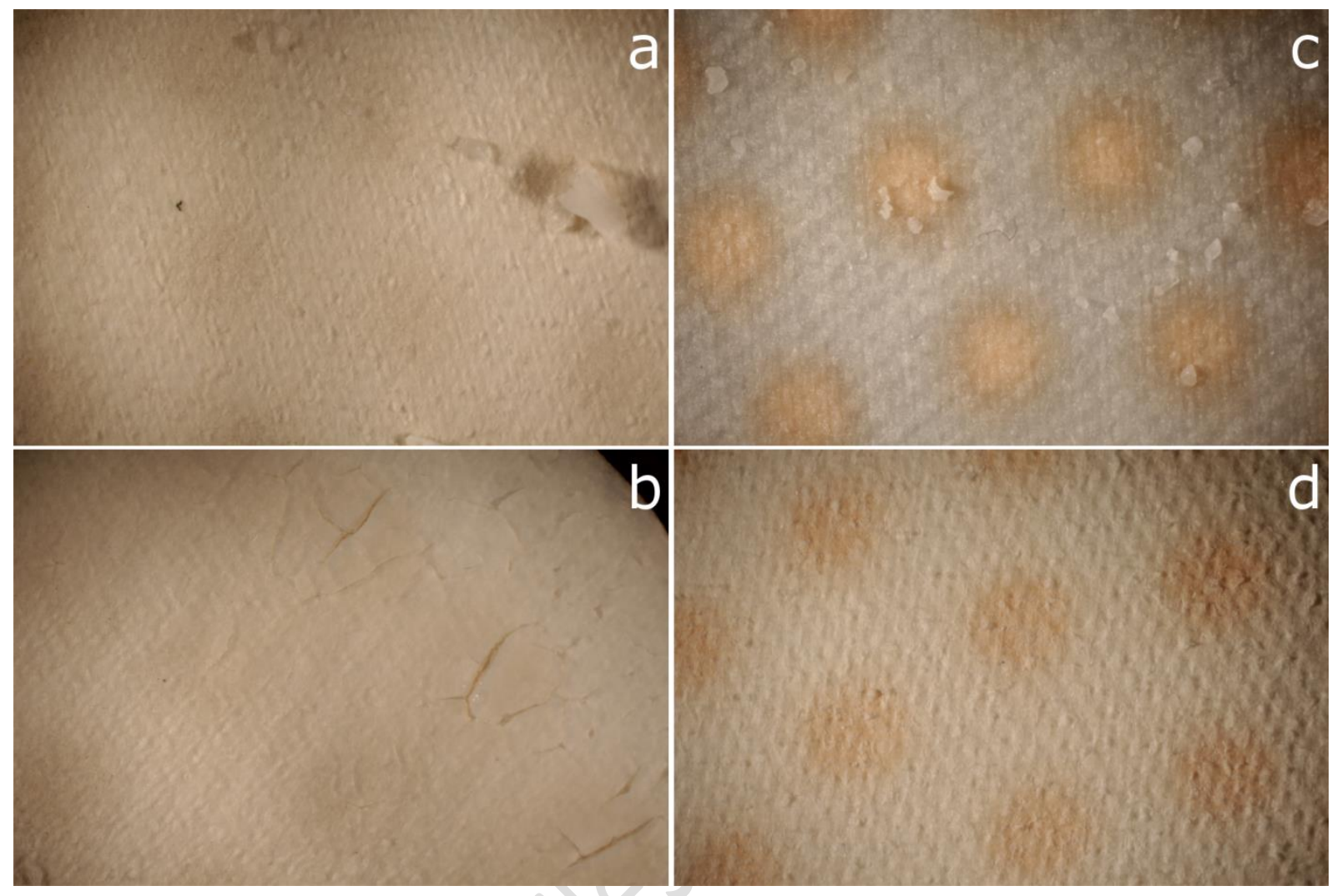

Filters corresponding to digestion of fish tissues (fillets and whole alimentary tract) with protocol $1 \mathrm{~b}(10 \%$ $\mathrm{KOH}, 24 \mathrm{~h}, 60^{\circ} \mathrm{C}$ ). Concerning fillet (a \& b), filters contain some fragments of bones partially digested (a). A fatty layer was noticed on the edge of filter (b). For whole alimentary tract (c \& d), a few fragments from the stomach content, such as cartilage or starfish remainings, were reported (c). Generally, filters were clear, lightly loaded and easily observable (d). 